\title{
Biological Characterization of Radiation Exposure and Dose Estimates for Inhaled Uranium Milling Effluents
}

\section{Annual Progress Report}

April 1, 1982 - March 31, 1983

Manuscript Completed: April 1984

Date Published: May 1984

Project Coordinator

A. F. Eidson

Inhalation Toxicology Research Institute

Lovelace Biomedical and Environmental Research Institute

Albuquerque, NM 87185

\section{Prepared for}

Division of Health, Siting and Waste Management

Office of Nuclear Regulatory Research

U.S. Nuclear Regulatory Commission

Washington, D.C. 20555

NRC FIN A1222

$$
\text { AcOH-76EVO1013 }
$$

\section{DISCLAIMER}

This report was prepared as an account of work sponsored by an agency of the United States Government. Neither the United States Government nor any agency thereof, nor any of their employees, makes any warranty, express or implied, or assumes any legal liability or responsibility for the accuracy, completeness, or usefulness of any information, apparatus, product, or process disclosed, or represents that its use would not infringe privately owned rights. Reference herein to any specific commercial product, process, or service by trade name, trademark, manufacturer, or otherwise does not necessarily constitute or imply its endorsement, recommendation, or favoring by the United States Government or any agency thereof. The views and opinions of authors expressed herein do not necessarily state or reflect those of the United States Government or any agency thereof. 


\section{DISCLAIMER}

This report was prepared as an account of work sponsored by an agency of the United States Government. Neither the United States Government nor any agency Thereof, nor any of their employees, makes any warranty, express or implied, or assumes any legal liability or responsibility for the accuracy, completeness, or usefulness of any information, apparatus, product, or process disclosed, or represents that its use would not infringe privately owned rights. Reference herein to any specific commercial product, process, or service by trade name, trademark, manufacturer, or otherwise does not necessarily constitute or imply its endorsement, recommendation, or favoring by the United States Government or any agency thereof. The views and opinions of authors expressed herein do not necessarily state or reflect those of the United States Government or any agency thereof. 


\section{DISCLAIMER}

Portions of this document may be illegible in electronic image products. Images are produced from the best available original document. 


\section{NOTICE}

This report was prepared as an account of work sponsored by an agency of the United States Government. Neither the United States Government nor any agency thereof, or any of their employees, makes any warranty, expressed or implied, or assumes any legal liability of responsibility for any third party's use, or the results of such use, of any information, apparatus. product or process disclosed in this report, or represents that its use by such.third party would not infringe privately owned rights.

\section{Availability of Reference Materials Cited in NRC Publications}

Most documents cited in NRC publications will be available from one of the following sources:

1. The NRC Public Document Room, 1717 H Street, N.W. Washington, DC 20555

2. The NRC/GPO Sales Program, U.S. Nuclear Regulatory Commission. Washington, DC 20555

3. The National Technical Information Service, Springfield, VA 22161

Although the listing that follows represents the majority of documents cited in NRC publications. it is not intended to be exhaustive.

Referenced documents available for inspection and copying for a fee from the NRC Public Document Room include NRC correspondence and ir.ternal NRC memoranda; NRC Office of Inspection and Enforcement bulletins, circulars, information notices, inspection and investigation notices; Licensee Event Reports; vendor reports and correspondence; Commission papers; and applicant and licensee documents and correspondence.

The following documents in the NUREG series are available for purchase from the NRC/GPO Sales Program: formal NRC staff and contractor reports, NRC.sponsored conference proceedings, and NRC booklets and brochures. Also available are Regulatory Guides. NRC regulations in the Code of Federal Regulations, and Nuclear Regulatory Commission /ssuances.

Documents available from the National Technical Information Servica include NUREG series reports and technical renorts prepared by other federal agencies and reports prepared by the Atomic Energy Commission, forerunner agency to the Nuclear Regulatory Commission.

Documents available from public and special technical libraries include all open literature items, such as books, journal and periodical articles, and transactions. Federal Register notices, federai and state legislation, and congressional reports can usually be obtained from these libraries.

Documents such as theses, dissertations, foreign reports and translations, and non-NRC conference proceedings are available for purchase trom the organization sponsoring the publication cired.

Single copies of NRC drath reports are available free upon written request to the Division of Technical Information and Document Control, U.S. Nuclear Regulatory Commission. Washington, DC 20555.

Copies of industry codes and standards used in a substantive manner in the NRC regulatory process are maintained at the NRC Library, 7920 Norfolk Avenue, Bethesda, Maryland, and are available there for reference use by, the public. Codes and standards are usually copyrighted and may be purchased from the originating organization or. if they are American National Standards, from the American National Standards Institute. 1430 Broadway. New York, NY 10018.

GPO Printed copy price: 400 
Biological Characterization of Radiation Exposure and Dose Estimates for Inhaled Uranium Milling Effluents, Annual Progress Report, March 1979-March 1980, NUREG/CR-1669, LMF-76.

Biological Characterization of Radiation Exposure and Dose Estimates for Inhaled Uranium Milling Effluents, Annual Progress Report, April 1980-March 1981, NUREG/CR-2539, LMF-94.

Biological Characterization of Radiation Exposure and Dose Estimates for Inhaled Uranium Milling Effluents, Annual Progress Report, April 1981-March 1982, NUREG/CR-2832, LMF-97. 


\section{ABSTRACT}

The problems addressed are the protection of uranium mill workers from occupational exposure to uranium through routine bioassay programs and the assessment of accidental worker exposures. Comparisons of chemical properties and the biological behavior of refined uranium ore (yellowcake) are made to identify important properties that influence uranium distribution patterns among organs. These studies will facilitate calculations of organ doses for specific exposures and associated health risk estimates and will identify important bioassay procedures to improve evaluations of human exposures.

A quantitative analytical method for yellowcake was developed based on the infrared absorption of ammonium diuranate and $\mathrm{U}_{3} \mathrm{O}_{8}$ mixtures in $\mathrm{KBr}$. The method allows the fraction of ammonium diuranate in a mixture to be determined accurately within $7 \%$; the $\mathrm{U}_{3} \mathrm{O}_{8}$ fraction is determined within 13\%. The method was applied to yellowcake samples obtained from six operating mills. The composition of yellowcake from the six mills ranged from nearly pure ammonium diuranate to nearly pure $\mathrm{U}_{3} \mathrm{O}_{8}$. The composition of yellowcake samples taken from lots from the same mill was only somewhat less variable.

Because uranium mill workers might be exposed to yellowcake either by contamination of a wound or by inhalation, a study of retention and translocation of uranium after subcutaneous implantation in rats was done. The results showed that $49 \%$ of the implanted yellowcake cleared from the body with a half-time $\left(T_{1 / 2}\right)$ in the body of 0.3 days, and the remainder was cleared with a $T_{1 / 2}$ of 11 to 30 days. Contrary to results of previous yellowcake inhalation studies using rats, the clearance from implanted rats was more rapid and could not be quantitatively related to yellowcake composition. An additional study of the effects of animal housing on response of rats to yellowcake nephrotoxicity showed that for studies requiring excreta collections, a minimum of 21 days should be provided for acclimation to metabolism cages before exposure.

Exposures of Beagle dogs by nose-only inhalation to aerosols of commercial yellowcake were completed. Twenty dogs exposed to a more soluble yellowcake form inhaled aerosols with $3.4 \pm 0.5 \mu \mathrm{m}$ mass median aerodynamic diameter (MMAD) (mean $\pm 1 \mathrm{SE}$ ) and $1.5 \pm .04$ geometric standard deviation (GSD) producing estimated initial lung burdens of $130 \pm 9 \mu \mathrm{g} \mathrm{U} / \mathrm{kg} \mathrm{body}$ weight. Aerosols inhaled by dogs exposed to a less soluble yellowcake form averaged $3.0 \pm 0.3$ um MMAD, with $1.7 \pm 0.1 \mathrm{GSO}$; the estimated initial lung burden was $140 \pm 7 \mu \mathrm{g} / \mathrm{kg}$ body weight. Biochemical indicators of kidney dysfunction that appeared in blood and urine 4 to 8 days after exposure to the more soluble yellowcake showed significant changes in dogs, but levels returned to normal by 16 days after exposure. No blochemical evidence of kidney dysfunction was observed in dogs exposed to the less soluble yellowcake form.

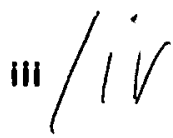




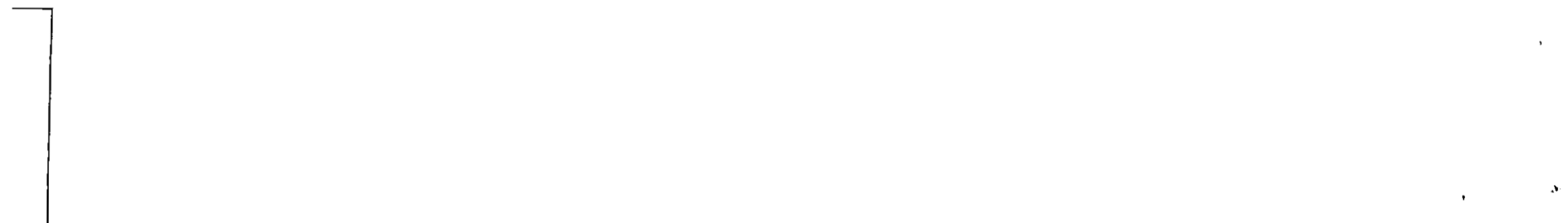




\section{TABLE OF CONTENTS}

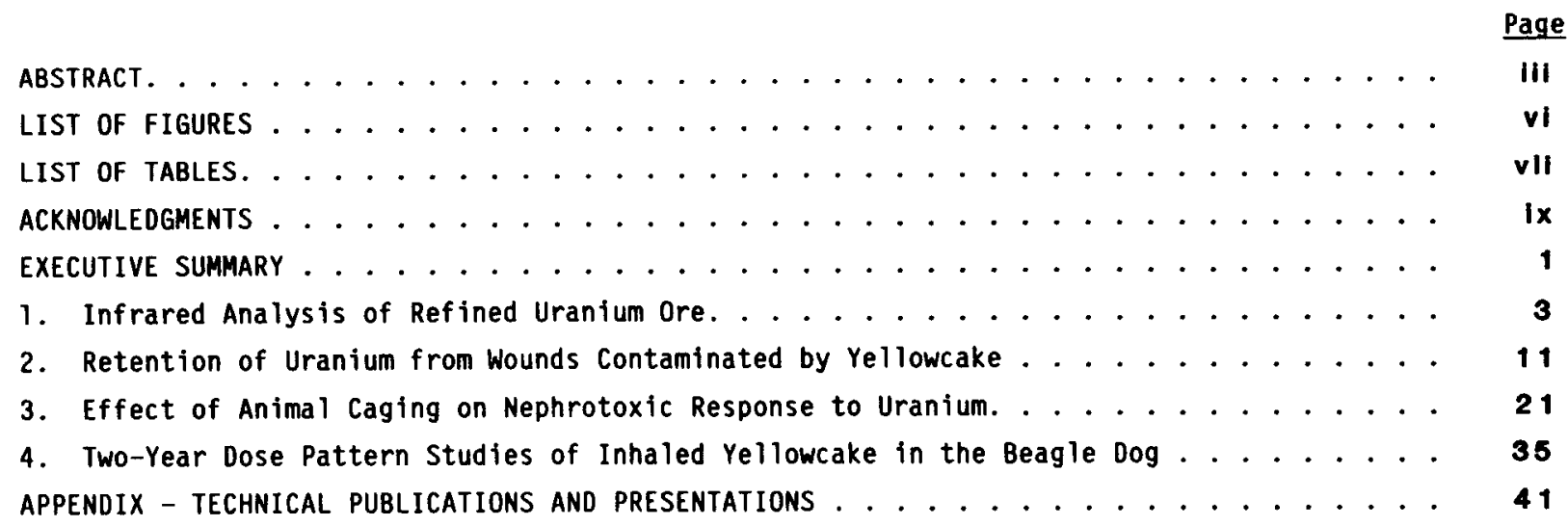


1. INFRAREO ANALYSIS OF REFINED URANIUM ORE

Figure 1.1

Figure 1.2

Figure 1.3

Figure 1.4

Figure 1.5
Infrared spectra of Mill B yellowcake before and after heating.....

Superposed spectra of ammonium diuranate and of $\mathrm{U}_{3} \mathrm{O}_{8} \ldots \ldots . . .$. Comparison of calculated composition of ammonium diuranate and $\mathrm{U}_{3} \mathrm{O}_{8}$

mixtures with their known values. . . . . . . . . . . . . . 6

Spectrum of a typical commercial yellowcake sample . . . . . . . . . 8

Spectra of samples taken from two drums from the same lot produced by

Mill E. ..........................

4

2. RETENTION OF URANIUM FROM SIMULATED WOUNDS CONTAMINATED BY YELLOWCAKE

Figure 2.1 Whole-body uranium retention curves for rats receiving subcutaneous implants of yellowcake from Mill A. . . . . . . . . . . . . . 14

Figure 2.2 Uranium content of kidneys in rats implanted with Mill A yellowcake. . 16

Figure 2.3 Uranium content of femurs in rats implanted with Mill A yellowcake. . . 16

Figure 2.4 Comparison of clearance of uranium from the implant site to uranium clearance from lung in rats exposed to yellowcake powder by inhalation. . . . . . . . . . . . . . . . . .

Figure 2.5 Whole-body uranium retention curves for rats receiving implants of

Mill A yellowcake at a dose of $10 \mathrm{mg} / \mathrm{kg}$ or at reduced doses of 1 or $3 \mathrm{mg} / \mathrm{kg}$........................ .

3. EFFECTS OF ANIMAL CAGING ON NEPHROTOXIC RESPONSE OF RATS TO URANIUM

Figure 3.1 Dose response curves for rats housed in metabolism cages beginning on the day of yellowcake implantation (Naive Rats) or for rats housed in polycarbonate cages or in metabolism cages beginning 21 days before yellowcake implantation (Acclimated Rats) . . . . . . . . . . .

Figure 3.2 Mean body weight of 10 rats housed in metabolism cages or in polycarbonate cages......................

Figure 3.3 Mean water consumption by 10 rats housed in metabolism cages or in polycarbonate cages. . . . . . . . . . . . . . . . .

Figure 3.4 Mean food consumption by 10 rats housed in metabolism cages or in polycarbonate cages .....................

Figure 3.5 Mean water consumption by rats implanted with $10 \mathrm{mg}$ yellowcake/kg body weight and housed in metabolism or polycarbonate cages. . . . . . . . .

Figure 3.6 volume of urinary output by rats following subcutaneous implantation with yellowcake.........................

Figure 3.7 Comparison of animal room temperature and temperatures recorded in polycarbonate cages or in metabolism cages during a 24-h cycle. . . .

Figure 3.8 Gross appearance of kidneys of naive rat that died 8 days after implantation of yellowcake at a dose of $10 \mathrm{mg} / \mathrm{kg} . \ldots . . . . .$. 
1. INFRARED ANALYSIS OF REFINED URANIUM ORE

Page

Table 1.1 Results of quantitative analys is of standard mixtures of ammonium diuranate and $\mathrm{U}_{3} \mathrm{O}_{8}$. . . . . . . . . . . . . . . . . . . . . T 7

Table 1.2 Analysis of yellowcake samples from six mills............ . 9

Table 1.3 Analysis of yellowcake samples from within each mill..........

2. RETENTION OF URANIUM FROM SIMULATEO WOUNDS CONTAMINATED BY YELLOWCAKE

Table 2.1 Uranium retention in the whole-body or at the wound site of rats receiving subcutaneous implants of yellowcake, compared to lung retention of uranium from inhaled yellowcake............ . 15

Table 2.2 Uranium distribution after subcutaneous implantation of yellowcake. . 15

Table 2.3 Uranium content of kidneys and femur, and daily urinary urinary excretion of uranium in rats receiving yellowcake implants . . . . 17

3. EFFECTS OF ANIMAL CAGING ON NEPHROTOXIC RESPONSE OF RATS TO URANIUM

Table 3.1 Effects of cage type on nephrotoxic response of rats to implanted yellowcake.......................

4. TWO-YEAR DOSE PATTERN STUDIES OF INHALED YELLOWCAKE

Table 4.1 Results of beagle dog exposures to aerosols of yellowcake powder containing $100 \%$ ammonium diuranate. . . . . . . . . . . . .

Table 4.2 Results of beagle dog exposures to aerosols of yellowcake powder containing $99 \% \mathrm{U}_{3} \mathrm{O}_{8} \ldots \ldots . . . \ldots . . . \ldots$ 


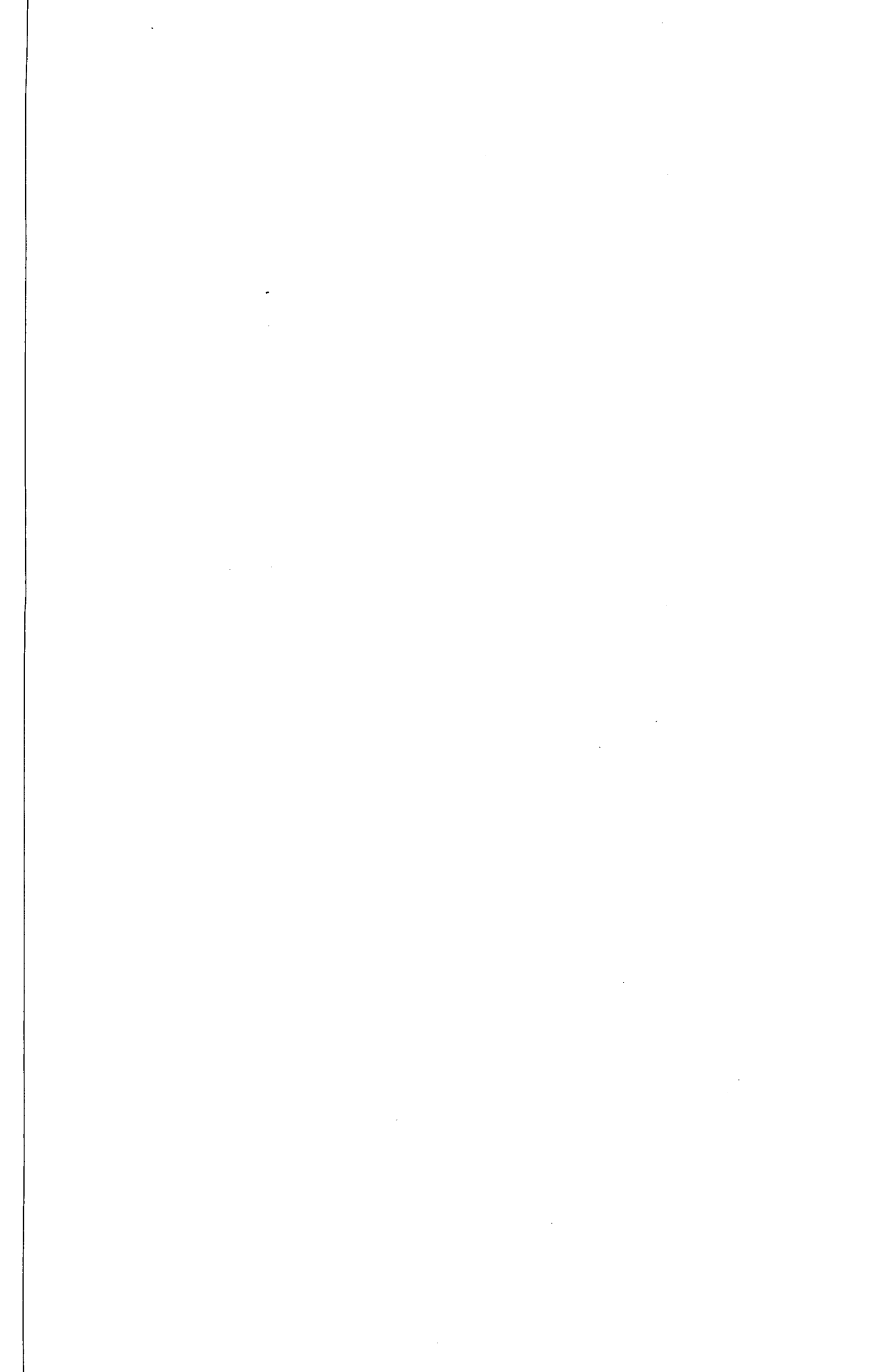

,
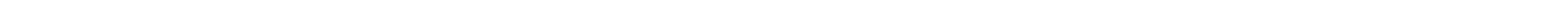


\section{Personnel Contributing to the Research}

\section{Senior and Associate Staff}
A. F. Eidson, Ph.D.
Chemist
E. G. Damon, Ph.D.
Radiobiologist
B. B. Boecker, Ph.D.
Radiobiologist
E. B. Barr, M.S.E.E.
Research Associate
D. H. Gray, M.S.
Chemist
F. F. Hahn, D.V.M., Ph.O.
Veterinary Pathologist
B. A. Muggenburg, D.V.M., Ph.D.
Research Veterinarian
J. A. Pickrell, D.V.M., Ph.D.
Clinical Chemist
H. C. Redman, D.V.M., M.P.V.M.
Research Veterinarian

\section{Technical Staff}

E. J. Otero, B.S.

J. A. Romero

A. C. Ferris, B.A.

\author{
Laboratory Technician \\ Laboratory Technician \\ Chief Research Technologist
}

It should be emphasized that a listing such as this is rarely comprehensive in acknowledging all the individuals who have made important contributions to the research. In the unnamed category are the many highly skilled animal care, maintenance, shop, administrative, and secretarlal personnel whose efforts are essential to the continuation of a productive research project. The authors acknowledge the friendly and helpful participation of the employees and management of the uranium mills studied to date. Research is performed in facilities fully accredited by the American Association for the Accreditation of Laboratory Animal Care. Research is sponsored by the U.S. Nuclear Regulatory Commission under an interagency agreement via U. S. Department of Energy Contract Number DE-ACO4-76EV01013. 
The purpose of this project is to provide scientific information to the $U$. S. Nuclear Regulatory Commission for its consideration in determining radiation protection guides and standards. This will ensure that the standards will protect adequately the health and welfare of mill workers and the public without placing unduly restrictive and expensive regulations on the mill operators.

U. S. Nuclear Regulatory Commission guides for worker protection in uranium mills are based on information derived from accidental human inhalation exposures to single chemical forms of uranium, such as $U_{2}, U_{3} 0_{8}, U F_{4}$ or $U F_{6}$. This is especially true for requirements for bioassay programs at uranium mills (R. E. Alexander. "Applications of Bioassay for Uranium," WASH-1251, 1974). Recommended procedures have since been revised to include more recent information, provided by this research program and others, that describes the composition of yellowcake as variable mixtures of ammonium diuranate and $U_{3} 0_{8}$, which vary in their solubility properties (U. S. Nuclear Regulatory Commission, "Bioassay at Uranium Mills," Regulatory Guide 8.22, for comment, 1978).

Much of the information used in the proposed procedures was derived from studies of yellowcake dissolution conducted in vitro using simulated biological fluids ( $D$. R. Kalkwarf, NUREG/CR-0530, 1979; A. F. Eidson and J. A. Mewhinney, Health Phys., 39, 893, 1980; N. A. Dennis, H. M. Blauer and J. E. Kent, Health Phys. 42, 469, 1982). There is inadequate information available from accidental worker exposures to actual yellowcake materials to evaluate the proposed procedures. It remains, then, to be shown how such information derived from experiments conducted in vitro can be used to predict the behavior of uranium inhaled by a mill worker.

The most important problem addressed in this project is the protection of uranium mill workers from occupational exposure to uranium, specifically through bioassay programs to assess the adequacy of worker protection. An additional consideration is the assessment of accidental exposures of workers and use of results to re-evaluate and modify protection programs, if necessary.

This report presents results of research conducted between April 1, 1982, and March 31, 1983, and includes individual papers prepared in several areas of research: (1) use of a quantitative analytical method to measure the variability in ammonium diuranate and $U_{3} 0_{8}$ contents of yellowcake samples a worker might be exposed to; (2) the results of two short-term studies in rats: one designed to relate the metabolism of yellowcake delivered via a simulated wound contamination for comparison to results of earlier yellowcake inhalation studies, and the second to investigate the effect of caging on the toxicity of implanted yellowcake; (3) the relationship of the amount of ammonium diuranate in aerosols inhaled by Beagle dogs to biochemical indicators of kidney toxicity.

This format reflects progress in the middle stage of a five-phase approach to the objectives of the project. First, limited sampling during miling operations was conducted to determine the properties of aerosols that a worker might inhale. The results were related to specific packaging steps and led to predictions of appreciable upper respiratory tract deposition rates for the aerosols, if inhaled. Second, laboratory analysis of yellowcake by infrared spectroscopy was used to quantify the range of composition variability of commercial yellowcake and to illustrate the use of such results in interpreting the results of animal studies or human bioassay data. 
Third, short-term inhalation studies using laboratory rats exposed to selected yellowcake powders were completed. A study designed to investigate the in vivo behavior of yellowcake deposited in a wound has shown that $49 \%$ of the body burden was cleared with a half-time ( $T_{1 / 2}$ ) of 0.3 days regardless of solubility. The remainder of the more soluble yellowcake cleared with a $T_{1 / 2}=11$ days, and the less soluble form cleared with a $T_{1 / 2}=30$ days. Both values were. more rapid than the half-times for clearance of inhaled yellowcake from lungs of rats ( $T_{1 / 2}$ $\sim 130$ days). The retention behavior of implanted yellowcake in rats could not be quantitatively related to yellowcake composition, as could the retention of inhaled yellowcake. An additional study on the effects of animal caging on the response of rats to nephrotoxicity showed that for studies requiring excreta collections, a minimum of 21 days should be provided for acclimation to metabolism cages before exposure. This should ensure that water consumption and nephrotoxic response will be similar to that of animals housed in polycarbonate cages.

A 2-year study of yellowcake aerosols from two uranium mills was continued. Aerosols were generated from a sample of yellowcake that was $100 \%$ ammonium diuranate (a more soluble form) and $>99 \% U_{3} 0_{8}$ (a less soluble form). Twenty dogs exposed to the more soluble yellowcake received an estimated initial lung burden of $130 \pm 9 \mu \mathrm{gU} / \mathrm{kg}$ body weight. Twenty dogs received an estimated initial lung burden of $140 \pm 7 \mu \mathrm{gu} / \mathrm{kg}$ of an aerosol of a less soluble yellowcake. Biochemical indicators of kidney dysfunction that appeared in blood and urine showed elevated levels that returned to normal within 16 days after exposure.

In the fourth phase, results of the animal studies will be used in future dose estimates and hazard evaluations of milling effluents. Distribution, retention, and excretion data from the 2-year studies will be compared with the physical chemistry results to identify the important yellowcake physical properties related to biological behavior. Fifth, data from the 2-year animal studies will be compared with available human data and incorporated into improved bioassay procedures as needed.

Uranium mills are identified alphabetically in this project. Identifying letters were assigned to each mill (Mills A through F) in the order we obtained their products and do not relate to the name of the mill, its location, or the parent company. 
1. INFRARED ANALYSIS OF REFINED URANIUM ORE

Abstract - The variability in chemical composition and solubility of commercial yellowcake products complicates the interpretation of bioassay data. PRINCIPAL INVESTIGATOR Quantitative infrared analysis was used to measure A. F. Bidson

the relative percentages of ammonium dturanate and $U_{3} O_{8}$ in comerclal yellowcake samples and to estimate the bounds of yellowcake composition variability. Analysis of standard mixtures showed that the ammonium diuranate in a mixture could be estimated within $\pm 7 x$ of the mixture and $U_{3} O_{8}$ could be estimated within 13x. Solutions to analytical difficulties such as overlapping spectral bands and sample variabtlity are discussed. Recommendations for establishtng infrared analysis procedures at other laboratorles are given.

Uranium ore is refined into a commercial product known as yellowcake, which is packaged as a dry powder for storage and shipment. Previous studies of airbone dust from yellowcake packaging operations (Ref. 1.1) have shown that, if inhaled, the majority of airborne yellowcake in uranium mills is likely to deposit in the nasopharyngeal region. Such particles, if insoluble, are cleared rapidly and excreted via the gastrointestinal tract. Material deposited in the pulmonary region is cleared by solubilization and excreted in urine, or retained in the lung, from which it is slowly cleared. The two major uranium compounds in yellowcake are ammonium diuranate and $\mathrm{U}_{3} \mathrm{O}_{8}$. Because ammonium diuranate is the more soluble of the two forms (Ref. 1.2$)$, and is absorbed and excreted in urine, chemical toxicity to kidney and deposition in bone are possible. However, the gradual accumulation of relatively insoluble $\mathrm{U}_{3} \mathrm{O}_{8}$ in lung might deliver an appreciable annual radiation dose to lung. Knowledge of the relative ammonium diuranate and $U_{3}{ }_{8}$ content of yellowcake is required to predict the possible target organs and nature of potential health effects from inhaled yellowcake.

Routine bioassay procedures are used to ensure that workers who might be exposed during their work do not accumulate undue amounts of internally deposited uranium. High variability has been observed in dissolution rates for yellowcake samples from four mills, complicating the interpretation of bioassay data (Ref. 1.2). In vitro dissolution studies (Refs. 1.2-1.4) are useful for studies of a few selected samples, such as a sample taken from a production lot involved in an accident, but they are impractical for use in a survey of yellowcake samples (Ref. 1.5). It is necessary to estimate the bounds of yellowcake variability to interpret bioassay data, either as part of routine monitoring or in evaluation of accidental exposures.

It has been shown that the more soluble percentage of a yellowcake sample can be estimated by quantitative infrared analysis (Ref. 1.2). Yellowcake contains ammonium diuranate as a mixture of a $\mathrm{UO}_{3}-\mathrm{NH}_{3}-\mathrm{H}_{2} \mathrm{O}$ adducts and their thermal conversion product $\mathrm{U}_{3} \mathrm{O}_{8}$ (Ref. 1.2) along with residues from the militing process (Ref. 1.3, 1.4). Although yellowcake is not strictly a binary mixture, the two oxide forms of uranium predominate. Figure 1.1 shows the infrared spectrum of a commercial yellowcake sample before and after heating at $150^{\circ} \mathrm{C}$ for $16 \mathrm{~h}$ and 11 lustrates the change that takes place in the infrared spectrum of yellowcake as the ammonium diuranate is converted to $\mathrm{U}_{3} \mathrm{O}_{8}$ upon heating.

The objectives of this study are to fllustrate a method to determine the variability among yellowcake lots, to define the assumptions involved, and to define the limits of application. The approach used quantitative infrared analysis of known mixtures of ammonium diuranate and $U_{3} 0_{8}$ 


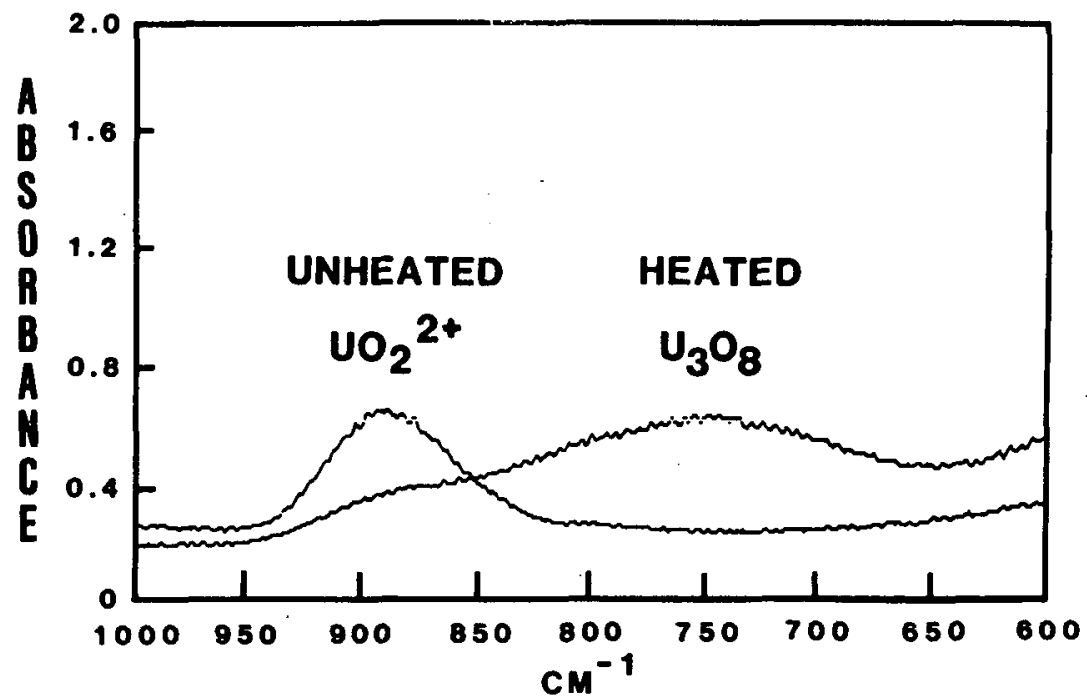

Figure 1.1 Infrared spectrum of yellowcake powder obtained from Mill B showing the appearance of a $\mathrm{U}_{3} \mathrm{O}_{8}$ band and the partial reduction in the $\mathrm{UO}_{2}+2$ intensity upon heating at $150^{\circ} \mathrm{C}$ for $16 \mathrm{~h}$. This illustrates the thermal conversion of the $\mathrm{UO}_{3}$ in ammonium diuranate to $\mathrm{U}_{3} \mathrm{O}_{8}$.

produced in the laboratory. The analysis of such standard mixtures was used to define the accuracy and precision of the technique. Then it was applied to unknown commercial samples. Two major difficulties were encountered. First was variability in ammonium diuranate forms that are produced in operating mills (and even from the same mill); and the second was overlapping ammonium diuranate and $\mathrm{U}_{3} \mathrm{O}_{8}$ infrared bands (Fig. 1.1). Solutions to these problems are discussed.

\section{MATERIALS AND METHOOS}

Ammonium diuranate was prepared in the laboratory by dropwise addition of $15 \%$ aqueous $\mathrm{NH}_{4} \mathrm{OH}^{\circ}$ to an aqueous solution of $\mathrm{UO}_{2}\left(\mathrm{NO}_{3}\right)_{2}$ with stirring at $\mathrm{PH} 7.0-7.5$ at room temperature. The resulting yellow precipitate was stirred for $16 \mathrm{~h}$, filtered, washed with cold water and acetone, and air-dried at room temperature. Eleven known mixtures of this ammonfum diuranate and $U_{3} O_{8}$ (National Lead Company, Cinninati, $\mathrm{OH}$ ) were prepared, with $\mathrm{Ox}$ ammonfum diuranate (pure $\mathrm{U}_{3} \mathrm{O}_{8}$ ) through 100\% ammonium diuranate (no $U_{3} 0_{8}$ present) in $10 \%$ intervals. The mixtures were ground in an agate vial using a Wigl-Bug shaker (Cresent Dental Manufacturing Company, Chicago, IL). A grinding time of $10 \mathrm{~min}$ provided maximum infrared absorbance for each component. Weighed aliquots of the mixtures were added to $1.0 \mathrm{~g}$ of desiccated spectral grade $\mathrm{KBr}$ to prepare mixtures that were $0.3 \%, 0.5 \%$, and $1.0 \%$ by weight. The ammonium diuranate $+U_{3} 0_{6}+K B r$ mixtures were also ground for $10 \mathrm{~min}$.

Pellets were prepared by pressing $200 \mathrm{mg}$ of the ground mixture at 2000 psi for 5 min using a hydraulic press (Fred $S$. Carver, Inc., Summit, NJ). Duplicate pellets were made for each mixture. Pellets of $\mathrm{KBr}$ alone were made similarly.

Yellowcake samples were obtained from six commercial mills (designated Mill A - Mill F), and pellet's that contained $0.3 \%$ sample in $\mathrm{KBr}$ were prepared as above. There was no pretreatment of yellowcake samples before grinding with $\mathrm{KBr}$.

Measurements were obtalned from all KBr pellets using a Perkin-Elmer Model 283B infrared spectrophotometer equipped with a microprocessor-controlled unit for quantitative anaiyses of mixtures using the Beer-Lambert law. 
Figure 1.2 shows superimposed spectra of pure ammonium diuranate and pure $\mathrm{U}_{3} \mathrm{O}_{8}$ on the same axes. The wavelengths chosen for analys is were taken from literature values (Ref. 1.6). The 925$\mathrm{cm}^{-1}$ peak and the $735-\mathrm{cm}^{-1}$ peak were assigned to ammonium diuranate and $U_{3} 0_{8}$. respectively. The two baseline points $\left(970\right.$ and $\left.636 \mathrm{~cm}^{-1}\right)$ were chosen as the relative minima of the pure samples. These relative minima were also appropriate for the unknown samples measured to date. The $852-\mathrm{cm}^{-1}$ peak was chosen for the $\mathrm{KBr}$ absorption peak. An attempt was made to use the minimum value (noted by the crossover of the two spectra as the $\mathrm{KBr}$ absorbance). Although this might be preferred, the absorbance at the crossover point was occasionally less then the baseline determined by the $970-\mathrm{cm}^{-1}$ and $636-\mathrm{cm}^{-1}$ peaks. The $852-\mathrm{cm}^{-1}$ value was chosen so that the errors caused would probably be overestimated.

One of the duplicate standard pellets of each known ammonium diuranate $+U_{3} 0_{8}$ mixture was selected randomiy. The absorbances of these pellets were used to obtain the absorbtivity matrix $a_{i, j}($ Eq. 1.1);

$$
A_{i, k}=a_{i, j} \times c_{j, k} \times b
$$

where: $A_{i, k}=$ absorbance at wavenumber $i\left(\mathrm{~cm}^{-1}\right)$ of mixture $k$,

$a_{i, j}=$ absorptivity at wavenumber $i$ of components $j$ of mixture $k$, $c_{j, k}=$ concentration (wx) of components $j$ of mixture $k$ in $k B r$. $b=$ constant pellet thickness $=0.052 \pm 0.001 \mathrm{~cm}$.

The remaining pellets of each pair were analyzed as unknowns. The process was then reversed to provide an analysis of all standard pellets as if they were unknowns. The concentrations of components in unknown yellowcake mixtures were then calculated using the absorbance spectrum and the absorptivity matrix as derived above.

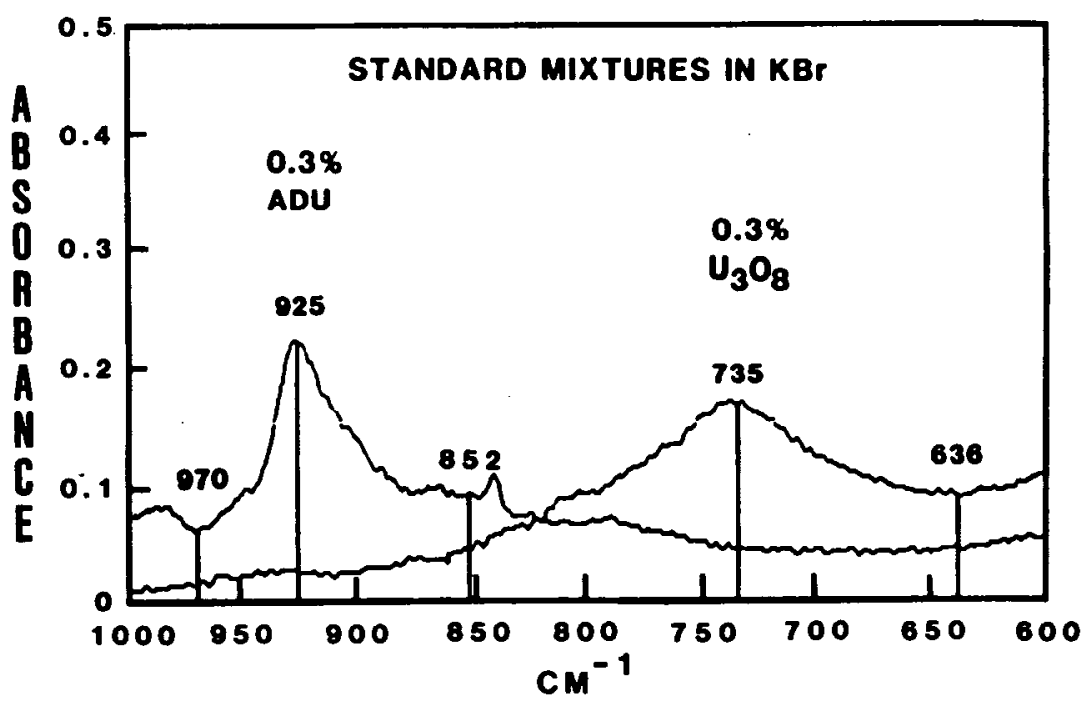

Figure 1.2 Superimposed infrared spectra of the $0.3 \%$ ammonium diuranate standard and $0.3 \%$ $\mathrm{U}_{3} \mathrm{O}_{8}$ standard. 


\section{RESULTS}

Figure 1.3 shows the results of the known ammonium diuranate $+U_{3} 0_{8}$ mixture analyses. Individual calculated values from repeated analyses are plotted versus known values relative to the theoritical line shown. A point above the line indicates an overestimate of the percentage of ammonium diuranate or $\mathrm{U}_{3} \mathrm{O}_{8}$ in the mixture. The points at $0 \%$ ammonium diuranate on Graph $A$ and $100 \% \mathrm{U}_{3} \mathrm{O}_{8}$ on Graph $\mathrm{B}$ represent analysis of the same pellets. Note that the method results in an underestimate for pure $U_{3} \mathrm{O}_{8}$, and the value for pure ammonium diuranate is less precise. The accuracy and precision of the results were greatest for mixtures containing $10 \%$ to $90 \%$ ammonium diuranate and $30 \%$ to $70 \% \mathrm{U}_{3} \mathrm{O}_{8}$. Given the above accuracy and precision of results of standard mixture analyses, results of unknown analyses showing $\leq 20 \%$ ammonium diuranate or $\mathrm{U}_{3} \mathrm{O}_{8}$ might indicate that the unknown mixture actually contained only ammonium diuranate or $\mathrm{U}_{3} \mathrm{O}_{8}$.
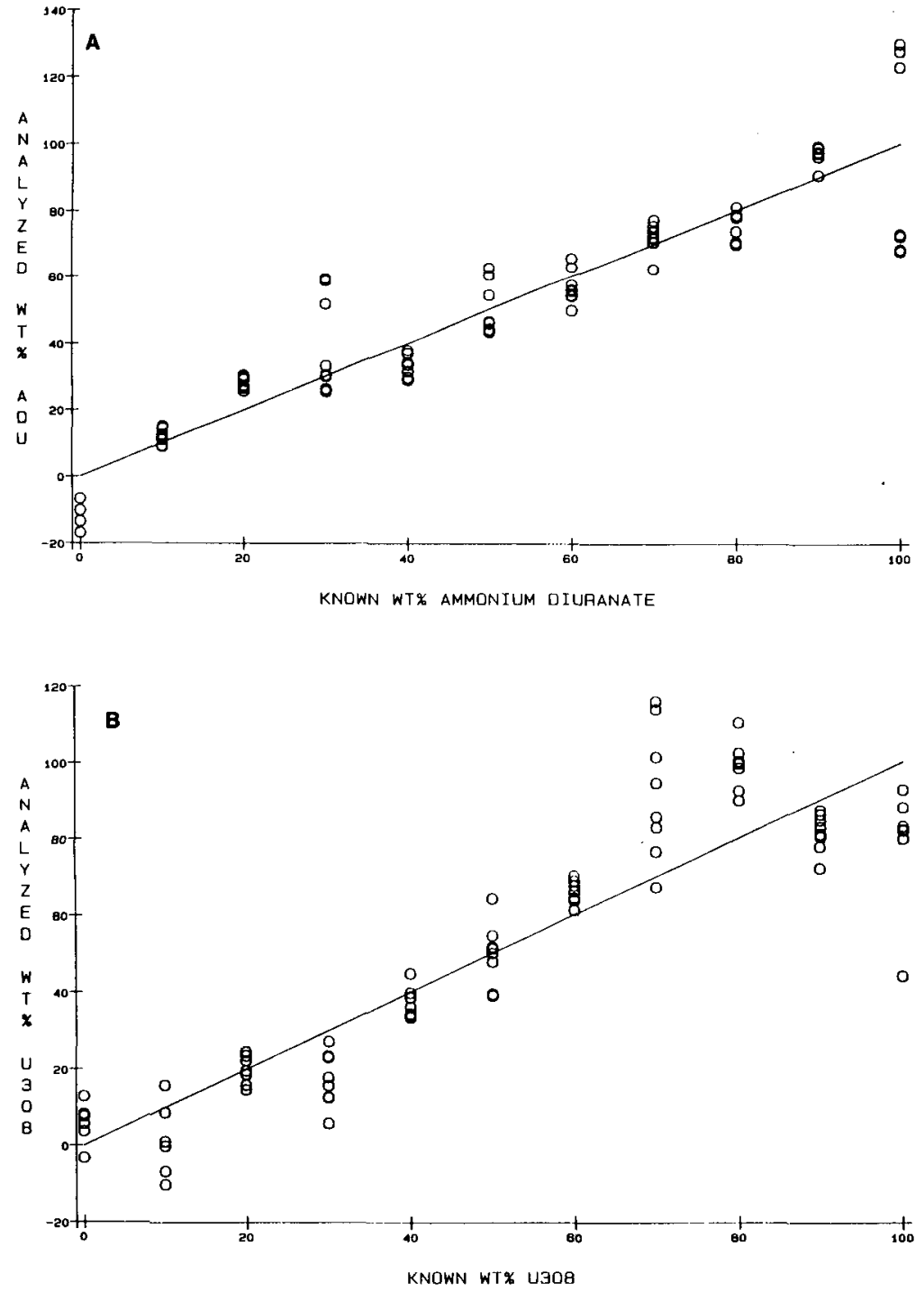

Figure 1.3 Standard ammonium diuranate $+U_{3} 0_{8}$ mixtures were analyzed as if they were unknowns. Total concentration of the mixtures in $\mathrm{KBr}$ was 0.3 wt $\%$. Graph $\mathrm{A}$ shows ammonium diuranate results, graph $B$ shows $\mathrm{U}_{3} \mathrm{O}_{8}$ results. 
Table 1.1 shows a summary of analyses of the 11 standard mixtures where the total concentration of uranium compounds in $\mathrm{KBr}$ was $0.3 \%, 0.5 \%$, and $1.0 \%$. The data are expressed as the difference between the analyzed and known amounts, such that a perfectly accurate and reproducable result would be $0.0 \pm 0.0$. The accuracy of the results shows that ammonium diuranate and $\mathrm{U}_{3} \mathrm{O}_{8}$ were generally overestimated, but not significantly so, when compared with the precision of the estimates. The number of analyses (22) reflects the analysis of duplicate pellets from 11 mixtures. Standard errors expressed in this way include the relatively large errors seen for the extremes of the concentration range (Fig. 1.3). Analyses of $0.3 \%$ pellets were shown to be more precise than those of $0.5 \%$ pellets. The precision of the $1.0 \%$ pellet analyses was comparable to that of the $0.3 \%$ pellets; however, the $0.3 \%$ pellets gave more precise results in the middle of the concentration range. This was assumed to be caused by decreased absorbance in the region of spectral overlap.

After the $0.3 \%$ pellets were chosen for routine use in the later analysis of unknowns, the standards were rescanned and analyzed four times during subsequent work. The results of these analyses were shown in Table 1.1 with $n=8$. The standard error values were greater but more reliable for routine work because they include possible instrumental error factors and possible changes in the standard pellets with time. The results of these four seperate scans and the analyses of the $0.3 \%$ pellets are shown in Fig. 1.3 .

The spectrum shown in Fig. 1.4 illustrates a typical commercial unknown sample. Note the broad ammonium diuranate peak that overlaps considerably with the $U_{3} 0_{8}$ peak. The initial analytical approach was to assume that any unknown sample was a mixture of ammonium diuranate and $U_{3} \mathrm{O}_{8}$. If the results suggested the yellowcake might be a pure form of either ammonium diuranate or $U_{3} \mathrm{O}_{8}$ and the spectrum appeared to be that of a pure form, the sample was reanalyzed using a calibration curve based on the pellets that contained only $0.3 \%$. $0.5 \%$ or $7.0 \%$ ammonium diuranate or $\mathrm{U}_{3} \mathrm{O}_{8}$. Analyses of suspected pure samples were based on peak areas rather than peak maximum absorbance. This was especially necessary in the case of pure ammonium diuranate samples (Fig. 1.5). The spectra shown in Fig. 1.5 illustrate the variability possible among grab samples from two drums from Lot \#55 produced by Mill $\mathrm{E}$. Note the absence of a $\mathrm{U}_{3} \mathrm{O}_{8}$ band. The two spectral bands in the orum \#42 sample can be assigned to peaks from $\mathrm{UO}_{2}^{+2}$

(Ref. 1.6). These spectra illustrate the most extreme case of this type of variability found to date. Clearly, analysis of this sample should use peak area rather than peak height methods.

Table 1.1

Analysis of Standard Mixtures of Ammontum Diuranate and $\mathrm{U}_{3} \mathrm{O}_{8}$ in $\mathrm{XBr}$ Deviation (Analyzed $x$ - Known Wt $x$ in Mixture)

Mean \pm SE (n)

Wt $x$ Mixture

in $\mathrm{KBr}$

0.3

0.3

0.5

1.0
Amnonfum Ofuranate

$0.43 \pm 2.6(22)$

$0.07 \pm 6.6$ (8)

$3.3 \pm 2.8(22)$

$0.1 \pm 3.2(22)$

\begin{tabular}{c}
$\mathrm{U}_{3} \mathrm{O}_{8}$ \\
\hline $0.51 \pm 6.3(22)$ \\
$-0.03 \pm 12.5(8)$ \\
$1.3 \pm 4.6(22)$ \\
$0.2 \pm 3.8(22)$
\end{tabular}




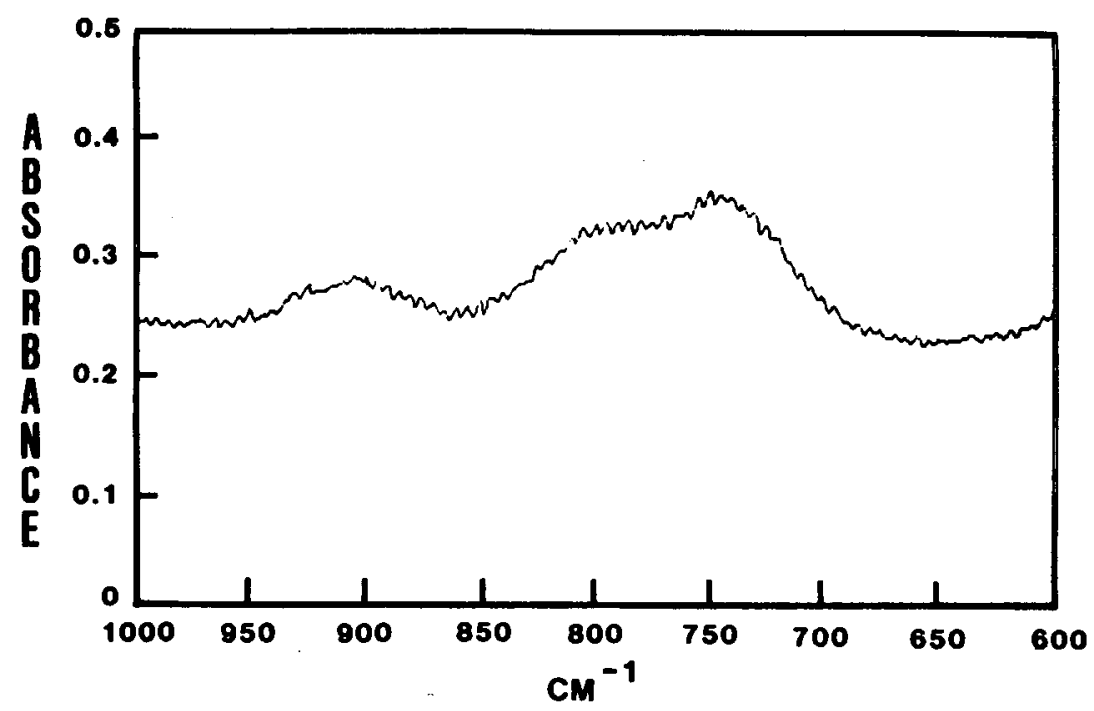

Figure 1.4 Infrared spectrum of yellowcake sample obtained from Mill $D$.

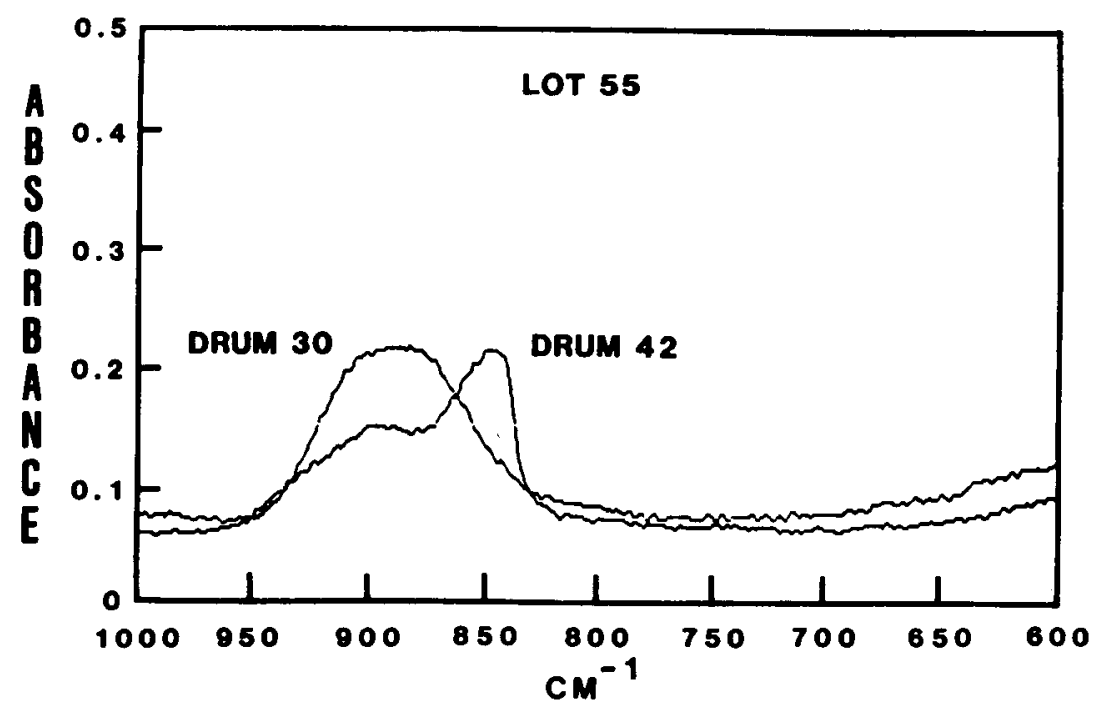

Figure 1.5 Infrared spectrum of yellowcake samples taken from two drums from Lot \#55 produced by Mill E.

Table 1.2 sumarizes analyses of samples taken from the mills studied to date. Mill A samples, shown in Table 1.2, might be considered to be pure ammonium diuranate and were reanalyzed as described. The sample from Mill $E$ was analyzed to contain $>100 x$ ammonium diuranate, an unreasonable result. The calculated value for $U_{3} 0_{8}$ might be artifactual when compared to the error in the ammonium diuranate result. Analysis as a pure ammonium diuranate sample indicated this was the case. The Mill B sample also showed an unreasonable result for ammonium diuranate analysis. Analysis as a pure sample did not resolve the question, and the sample was considered to contain $86 \pm 5 \%$ ammonium diuranate, with the remainder $U_{3} O_{8}$. Analysis of the Mill $C$ sample suggested it might contain only pure $\mathrm{U}_{3} \mathrm{O}_{8}$; however, the spectrum showed a small 
ammonium diuranate absorbence peak. Thus, reanalysis as a pure $U_{3} 0_{8}$ sample was not considered. No sample from any mill studied to date could be considered to be pure $U_{3} 0_{8}$; each suspected pure sample contained a fraction of ammonium diuranate, showing that thermal conversion to $U_{3} O_{8}$ was not complete.

Table 1.2

Analysis of Yellowcake Samples of Unknown Composition

From Six Mills As Mixtures and Pure Components

Mi11

A
B
C
D
E
F

Wt $x$ Mixture Analysis ADU

$$
53 \pm 10^{\mathrm{a}}
$$$$
111 \pm 4^{a}
$$

$17 \pm 1^{a}$

$25 \pm 2$

$129 \pm 5^{a}$

$49 \pm 3$

\section{$\mathrm{U}_{3} \mathrm{O}_{8}$}

$1 \pm 2^{\mathrm{a}}$

$16 \pm 3$

$56 \pm 1$

$71 \pm 2$

$25 \pm 2^{a}$

$53 \pm 4$
(Mean \pm SE)

Analys is as Pure Component

$\underline{A D U} \quad \underline{\mathrm{U}_{3} 0_{8}}$

$90 \pm 20$

$86 \pm 5$

Not a pure spectrum

$99 \pm 6$

${ }^{a}$ Values are within the $\pm 20 \%$ uncertainty for mixture analysis. Samples were reanalyzed as pure components after inspection of the spectrum.

Note that samples such as that shown for Mill $C$, which indicate less than loox combined ammonium diuranate $+U_{3} \mathbf{O}_{8}$, might occur in practice. Other species from the milling process might represent up to $6 \%$ of the final product (Ref. 1.3, 1.4), and residual water and $\mathrm{NH}_{3} \mathrm{Can}$ also be present. A sample that might be incompletely dried or refined and not meet production requirements might still be inhaled by a worker and require analysis.

Table 1.3 summarizes the range in ammonium diuranate content of different lots from one mill. It is clear that there is variability among products from a single mill (Fig 1.5 ) just as there is among products from different mills. The greatest variability was observed in Mill D yellowcake; the most constant ammonium diuranate percentage was in Mill $F$ yellowcake.

Table 1.3

Analysis of Unknown Samples Obtained From Different Lots From Each Mill

Mill
B
C
D
E
F

\section{Wt $\$$ AOU (Mean \pm SE)}

\begin{tabular}{rr}
\hline \multicolumn{1}{c}{ Min } & \multicolumn{1}{c}{ Max } \\
$77 \pm 5$ & $100 \pm 10$ \\
$1 \pm 1$ & $17 \pm 1$ \\
$4 \pm 1$ & $55 \pm 3$ \\
$63 \pm 6$ & $100 \pm 10$ \\
$46 \pm 3$ & $64 \pm 4$
\end{tabular}

\section{DISCUSSION}

These results illustrate the use of infrared analysis to accurately analyze ammonium diuranate in the presence of $U_{3} 0_{8}$ to within $\pm 7 x$ standard error of the mean. Similarly, the $U_{3} 0_{8}$ 
content can be analyzed accurately to within $\pm 13 \%$. These accuracy and precision values are well within the variability in yellowcake composition observed for lots produced by different mills and for lots produced within the same mill at different times.

The following actions are recommended for those wishing to apply this technique to yellowcake anatysis:

1. Standard and unknown pellets should be scanned at the same time or without turning off the instrument, and the instrument should be thoroughly warmed up.

2. A dried but unheated sample of yellowcake precipitate from each facility should be used as the pure ammonium diuranate standard.

3. If experience shows that spectra of successive lots from one mill are especially variable (see Fig. 1.5), standard mixtures of $\mathrm{U}_{3} \mathrm{O}_{8}$ and each ammonium diuranate form should be considered.

4. A collection of such standard mixtures and analytical results should be maintained to determine the overall variability in the composition of yellowcake from the facility.

\section{REFERENCES}

1.1 A. F. Eidson and E. G. Damon, "Predicted Deposition Rates of Uranium Yellowcake Aerosols Sampled in Uranium Mills," Health Physics (in press).

1.2 A. F. Eidson and J. A. Mewhinney, "In Vitro Solubility of Yellowcake Samples From Four Uranium Mills and the Implications for Bloassay Interpretation," Health Physics 39, 893-902 (1980).

1.3 D. R. Kalkwarf, "Solubility Classification of Airborne Products From Uranium Ores and Tailings Piles," NUREG/CR-0530, PNL-2870, 1979.

1.4 N. A. Dennis, H. M. Blauer, and J. E. Kent, "Dissolution Fractions and Half-Times of Single Source Yellowcake in Simulated Lung Fluids," Health Physics 42, 469-477 (1982).

1.5 A. F. Eidson and W. C. Griffith, Jr.. "Techniques for Yellowcake Dissolution Studies In Vitro and Their Use in Bioassay Interpretation," Health Physics (in press).

1.6 A. M. Deane, "The Infra-red Spectra and Structure of Some Hydrated Uranium Trioxides and Ammonium Diuranates," Journal of Inorganic and Nuclear Chemistry 21, 238 (1961). 


\section{RETENTION OF URANIUM FROM SIMULATEO WOUNOS CONTAMINATEO BY YELLOWCAKE}

Abstract - The translocation and retention of urantum from two different yellowcake samples subcutaneously implanted in rats to simulate contamination of wounds was assessed. Forty-five rats, anesthetized with halothane, were subcutaneously implanted with powders of each of the two yellowcake samples at a dose of $20 \mathrm{mg} \mathrm{J} / \mathrm{kg}$. Rats were sacrlf1ced 1 h groups of 5 at intervals through 32 days after implantation. Selected tissues and excreta samples were assayed by fluorometry to determine their uranium content. Two-component negative exponential functions were fitted to the uranium body burdens expressed as percentages of the initially implanted uranium body burdens. For both yellowcake samples, $45 \%$ of the initial body burden (IBB) cleared with $T_{1 / 2}$ of 0.2 days. The remaining $55 \%$ of the IBB cleared with $T$. $1 / 2$ of 10 days for the first yellowcake sample and 28 days for the second sample. Results of prior studies of lung clearance of uranium from thhaled aerosols of the two yellowcake samples showed an early clearance component $\left(T_{1 / 2}=I\right.$ day) that correlated with the ADU percentage and a late clearance component $\left(T_{1 / 2}=180\right.$ days $)$, which corresponded to the $U_{3} O_{8}$ percentage composition of the inhaled yellowcake. Thus uranlum clearance from subcutaneously lmplanted yellowcake was more rapld than uranium clearance from yellowcake deposited in lung.

Uranium mill workers may be exposed to uranium compounds by inhalation, ingestion, wound contamination, or by absorption from the eyes or mucous membranes. An earlier work described the lung retention and translocation of uranium from inhaled yellowcake aerosols (Ref. 2.1). This report presents results of studies of whole-body retention and translocation of uranium after subcutaneous implantation of yellowcake powder in rats to simulate contamination of wounds.

Although toxicologic studies on dermal application of uranium compounds have been conducted (Ref. 2.2), absorption of yellowcake powder or uranium compounds from contaminated wounds has not been investigated. The objective of the study was to determine the rate of absorption and the patterns of retention, translocation, and excretion in rats exposed to one of two samples of yellowcake powder implanted subcutaneously. The two yellowcake samples differed widely in in vitro solubility (Ref. 2.3). This report presents data on the pattern of whole-body retention of uranium as related to the composition of the implanted yellowcake powder. Data on retention of uranium at the site of implantation and translocation of uranium to kidneys and bone and the pattern of urinary excretion of uranium are also presented.

\section{MATERIALS AND METHODS}

\section{Yellowcake Powders}

Two yellowcake powders with known solublitity properties were selected for these studies. One powder obtained from M111 A contained $82 \%$ of its total uranium in a soluble form, ammonium diuranate (ADU), and $\sim 18 \% \mathrm{U}_{3} \mathrm{O}_{8}$, a relatively insoluble compound. The second powder, from Mill D, was composed of $\sim 25 \%$ ADU and $75 \% \mathrm{U}_{3} 0_{8}$. These powders were chosen to provide data for comparison with the results of in vivo studies using rats exposed by inhalation to aerosols of the same two materials (Ref. 2.1). 
Anima 1s

Fifty male F-344, specific pathogen-free, laboratory-reared rats, 10-12 weeks of age, were initially selected for each yellowcake sample used. The mean \pm 1 S.E.M. of the body weights was $260 \pm 4 \mathrm{~g}$. Rats were fed Lab Blox (Allied Mills, Chicago, IL) and watered ad libitum. Water bottles were changed two times a week. Rats were housed individually in polycarbonate cages (45 $x$ $25 \times 20 \mathrm{~cm}$ ) containing a bedding of wood chips or aspen wood shavings (American Excelsior, 0shkosh, WI). All cages were changed weekly. Four rats implanted with each material were individually housed in stainless steel wire-mesh-bottom cages $(18 \times 18 \times 25 \mathrm{~cm}$, Wahman's Manufacturing Co., Timonium, MD) during the time excreta were collected. After excreta collection, the rats were individually housed in polycarbonate cages. Animal rooms were maintained on a $12-\mathrm{h}$ light cycle $\left(6 \mathrm{a} . \mathrm{m}\right.$. to $6 \mathrm{p.m}$.) at temperatures of $20-23^{\circ} \mathrm{C}$ and a relative humidity of 30 to $50 \%$.

\section{Yellowcake Implantations}

Anesthesla was induced in rats with a $5 \%$ mixture of halothane (Halocarbon Laboratories, Inc., Hackensack, NJ) vaporized in $95 \% \mathrm{O}_{2}$ at a flow rate of $0.6 \mathrm{~L} / \mathrm{min}$ and maintained with $2 \%$ halothane administered by a face mask. The hair was clipped from the dorsal thoracic area and an incision 1 $\mathrm{cm}$ long was made on the dorsal midline between the scapulae. The dorsal midline was chosen for the implant to prevent the rat from removing the sutures during grooming. Yellowcake $(10 \mathrm{mg} \mathrm{U} / \mathrm{kg}$ of body weight) was implanted subcutaneously, and the skin was sutured with VETAFIL BENGEN - (S. Jackson, Inc. Washington, DC). The incision was then sprayed with Aeroplast spray-on plastic dressing (Parke-Davis and Co., Greenwood, SC). Selection of the dose was based on the following assumptions :

(1) Absorption of a subcutaneous implant of a soluble uranium powder was expected to be no greater than that of an intraperitoneal injection of an aqueous uranium solution. Haven and Hodge (Ref. 2.4) reported an L050 value of $86 \mathrm{mg} \mathrm{U} / \mathrm{kg}$ after $48 \mathrm{~h}$ in 200-300 $\mathrm{g}$ male Wistar rats after an intraperitoneal injection of a $10 \%$ aqueous solution of uranyl nitrate. The dose used in our study was selected to be approximately one-tenth of the $\mathrm{LO}_{50 / 48} \mathrm{~h}^{\text {. }}$

(2) The materials used in these studies were expected to release uranium more slowly than an intraperitoneal injection of solution.

Implantations of either material at a dose of $10 \mathrm{mg} U / \mathrm{kg}$ were made in 45 rats. Five rats were surgically sham-implanted and retalned as controls. Because rats housed in metabolism cages died after implantation with the more soluble yellowcake (Ref. 2.5), rats dying as a result of nephrotoxicity were replaced with rats implanted at the same dose level or at reduced dose levels ( 5 or $3 \mathrm{mg} \mathrm{U} / \mathrm{kg}$ ). An additional 15 rats (in groups of 5) were also implanted with Mill A yellowcake at reduced doses of 3 or $1 \mathrm{mg} \mathrm{U/kg}$ and were housed in polycarbonate cages. Uranium retention curves for these rats were compared to those for rats implanted with the same yellowcake at a dose of $10 \mathrm{mg} \mathrm{U} / \mathrm{kg}$ to assess effects of dose on retention of the M111 A yellowcake.

\section{Excreta Collection Schedule}

Urine, feces, and cage-wash samples were collected from two of the rats in each of the 16- and 32-day sacrifice groups. These samples were collected dafly for four days after implantation. Three-day composite collections were then made weekly until sacrifice. Excreta samples from two of the control rats were collected on the same schedule as that of the 32-day sacrifice group. 


\section{Sacrifice Schedule}

At intervals of $2 h, 1,2,3,4,8,16$, and 32 days after implantation, rats were sacrificed in groups of five by means of an intraperitoneal injection of $1 \mathrm{ml}(50 \mathrm{mg})$ of sodium pentobarbital. followed by exsanguination by heart puncture. Rats housed in polycarbonate cages and implanted with Mill A yellowcake at reduced dose levels $(1$ or $3 \mathrm{mg} \mathrm{U} / \mathrm{kg}$ ) were sacrificed at 8 or 16 days after implantation.

Rats were weighed before sacrifice, and the organs were weighed at necropsy. Fluorometric assay for uranium (Ref. 2.1) was conducted on the following tissues from each rat:

1. Blood samples collected by heart puncture at sacrifice.

2. Lung

3. Kidney

4. Section of soft tissue surrounding the site of the implantation $12 \times 2 \mathrm{~cm}$ excised to the depth of the vertebral column)

5. Liver

6. Both femurs

7. Remaining carcass and skin.

A central section cut longitudinally from one of the kldneys was preserved in $10 \%$ neutral buffered formalin for histopathological studies.

\section{Analysis of Retention Data}

The uranium contents of the tissues were expressed as percentages of the uranium implanted initially, i.e., the initial body burden (IBB).

Two-component negative exponential functions (Eq.1) were fitted to the whole-body retention data by a nonlinear least squares technique (Ref. 2.6):

$$
X I B B(t)=A_{1} e^{-0.693(t) / T_{1}}+A_{2} e^{-0.693(t) / T_{2}}
$$

where $A_{1}$ and $A_{2}$ are early and late retention components in percent, $t$ is time after exposure in days, and $T_{1}$ and $T_{2}$ are the clearance half-times for components $A_{1}$ and $A_{2}$, respectively. Similar functions (Eq. 1) were also fitted to the uranium retention data for the soft tissue surrounding the site where the yellowcake was implanted (wound-site). Single-component negative exponential functions (Eq. 2) were fitted to retention data for rats housed in polycarbonate cages and sacriffced at 8 . or 16 days after implantation with Mill A yellowcake at reduced dose levels ( 1 or $3 \mathrm{mg} \mathrm{U} / \mathrm{kg}$ ).

$$
X I B B(t)=A e^{-0.693(t) / T}
$$

Retention functions for the two groups exposed to Mill A and Mill D yellowcake were compared to determine effects of composition of the implanted yellowcake powder on urantum retention. Levels of significance of differences between uranium retention curves for the different groups were determined by F-Tests (Ref. 2.6).

Uranium content of kidneys, bone (femur), and the urinary excretion of uranium for rats implanted with the two materials were compared by analyses of variance and significance of differences between groups was determined by F-Tests (Ref. 2.6). 
The $10 \mathrm{mg} \mathrm{U} / \mathrm{kg}$ dose was considered low enough that no acute biological effects were expected but high enough that the concentration of uranium in the tissues of sacrificed rats at times up to 32 days after exposure could be measured by fluoromotric procedures. However, rats exposed to the Mill A yellowcake - the initial four rats housed in metabolism cages - died 8 days after implantation. Gross observations at necropsy revealed signs of uranium toxicity to the kidneys (Ref. 2.5). Kidneys appeared pale, with mottled reddish coloration and yellowish speckling. None of the rats exposed to the Mill A yellowcake and housed in polycarbonate cages showed any acute effects from the treatment. No acute effects were observed in rats exposed to the Mill $D$ yellowcake or in the sham-implanted control rats. The gross appearance of kidneys from the surviving rats was normal when the rats were sacrificed 16 and 32 days after exposure. An experiment to investigate the effects of differences in types of caging on the response of rats to uranium is described in the next paper in this report.

Whole-Body Retention of Uranium

Figure 2.1 shows the whole-body uranium retention curves for the two yellowcake samples, and the parameters for the retention functions are listed in Table 2.1. For both materials, 45\% IBB cleared with a half-time of < 1 day, the remaining 55\% IBB cleared with $T_{1 / 2}$ of 10 days for the Mill A yellowake and 28 days for Mill $D$. Whole-body retention functions for the two yellowcake samples were significantly different $(P<0.005)$.

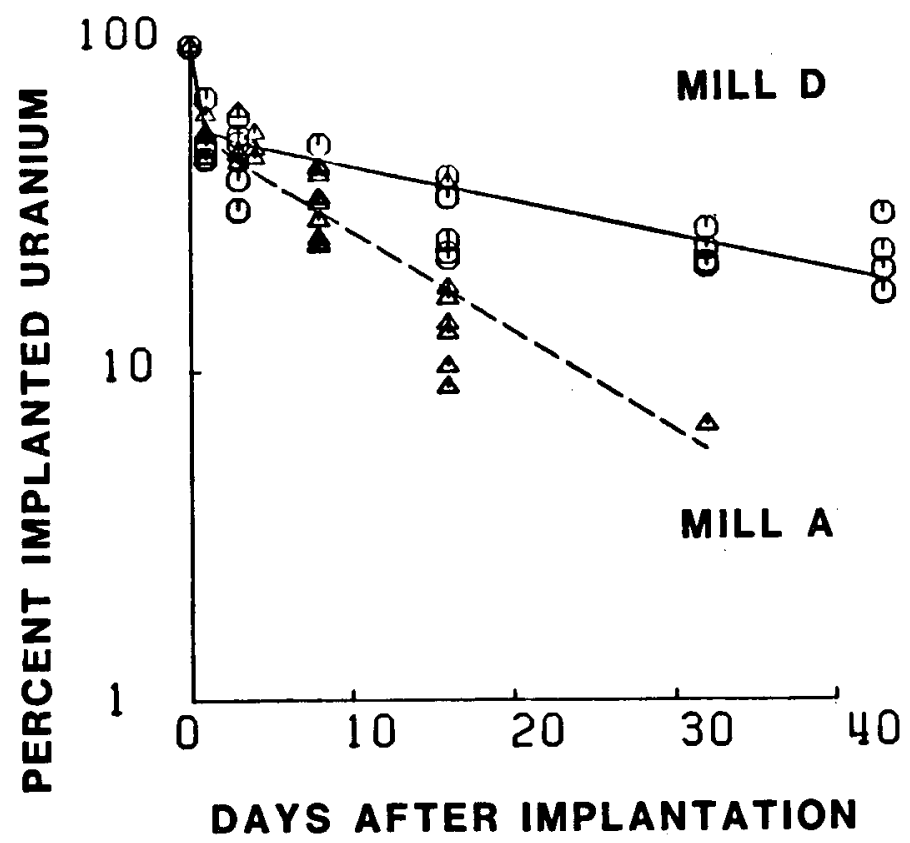

Figure 2.1. Whole-body uranium retention curves for rats receiving subcutaneous implants of yellowcake from Mill A (lower curve, data as triangles) or Mill D (upper curve, data as circles).

Table 2.2 shows the distribution of uranium between the implantation site (wound) and other tissues (primarily kidney and bone) in rats sacrificed 1, 8, or 32 days after implantation.

Figures 2.2-2.3 show comparisons of the uranium contents of kidneys and femurs of rats sacrificed after implantation with the two yellowcake materials. Results of analysis of variance of all of the kidney and femur data for rats sacrificed from 1 to 32 days after implantation with 
Table 2.1

Uranium Retention in the whole Body or at the Wound

Site of Rats Implanted Subcutaneously with Yellowcake

Yellowcake Sample

\begin{tabular}{cccc}
\multicolumn{4}{c}{ Retention $^{\text {Parameters }}{ }^{\mathrm{a}}$} \\
\hline${ }^{\mathrm{A}_{1}}$ & $\mathrm{~T}_{1}$ & $\mathrm{~A}_{2}$ & $\mathrm{~T}_{2}$ \\
$(\boldsymbol{( x )}$ & (days) & $-(\%)$ & (days) \\
\hline
\end{tabular}

Mill A:

$\begin{array}{llllr}\text { Whole Body } & 45 \pm 3 & 0.2 \pm 0.1 & 55 \pm 3 & 10 \pm 1 \\ \text { Wound site } & 55 \pm 3 & 0.2 \pm 0.1 & 45 \pm 3 & 8 \pm 1 \\ \text { Lung }^{b} & 70 \pm 6 & 1.0 \pm 0.3 & 30 \pm 6 & 68 \pm 30\end{array}$

Mi11 D:

$\begin{array}{lllll}\text { Whole Body } & 45 \pm 4 & 0.2 \pm 0.1 & 55 \pm 4 & 28 \pm 3 \\ \text { Wound site } & 55 \pm 3 & 0.2 \pm 0.1 & 45 \pm 3 & 30 \pm 3 \\ \text { Lung }^{b} & 15 \pm 13 & 1.0 \pm 0.3 & 85 \pm 13 & 68 \pm 30\end{array}$

$a_{\% \operatorname{IBB}(t)}=A_{1} e^{-0.693(t) / T_{1}}+A_{2} e^{-0.693(t) / T_{2}}$

b Based on data from Ref. 2.1.

Retention functions for the two yellowcake samples are significantly different for both the whole body and the implant site $(P<0.005)$. Retention functions for lung were significantly different from those for implant site $(p<0.005)$.

Table 2.2

Uranium Distribution After Subcutaneous Implantation of Yellowcake

Days After

Exposure

\section{1}

8

32
Uranium Content. Percent of Implanted Uranium

\begin{tabular}{llll}
\hline \multicolumn{2}{c}{ Implant Site } & \multicolumn{2}{c}{ Other Tissues } \\
\cline { 2 - 2 } & $\underline{\text { MILL D }}$ & MILL A & MILL D \\
\hline $42 \pm 3$ & $48 \pm 5$ & $12 \pm 2$ & $6 \pm 0.5$ \\
$25 \pm 3$ & $38 \pm 3$ & $12 \pm 2$ & $2 \pm 0.7$ \\
$3 \pm 0.4$ & $20 \pm 2$ & $4 \pm 0.5$ & $3 \pm 0.2$
\end{tabular}




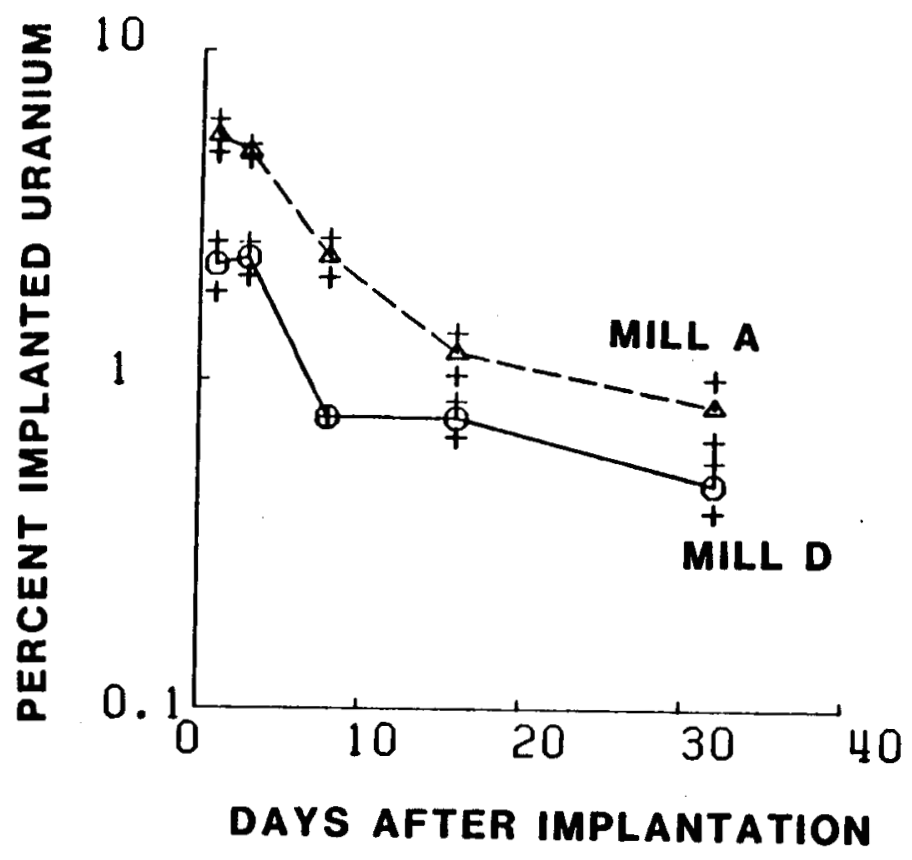

Figure 2.2. Uranium content of kidneys of rats reciving implants of Mill A (dashed line data as triangles) or Mill D yellowcake (solid line, data as circles). Data points are mean values and error bars indicate \pm 1 S.E.M.

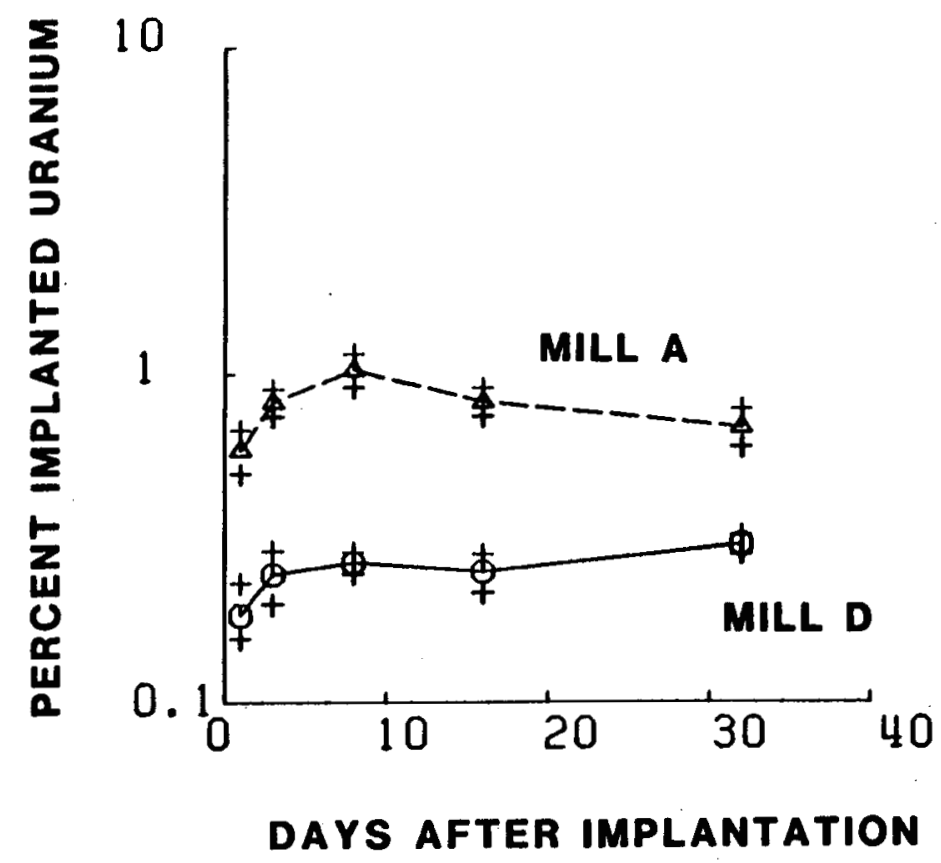

Figure 2.3. Uranium content of femurs in rats Implanted with Mil1 A (dashed line, data as triangles) or M111 D yellowcake (solid line, data as circles). Data points are mean values and error bars indicate \pm 1 S.E.M. 
yellowcake are listed in Table 2.3. The mean uranium content of both kidneys and femurs was significantly higher in rats implanted with the Mill A yellowcake than in those implanted with the Mi11 D material during the 32 days of the study $(p<0.01$ for kidneys and $p<0.0001$ for femurs).

Table 2.3

Uranium Content of Kidneys, Femur, and Daily Urinary

Excretion of Uranium in Rats Receiving Yellowcake Implants

\begin{tabular}{|c|c|c|c|}
\hline \multirow[b]{2}{*}{$\begin{array}{l}\text { Yellowcake } \\
\text { Sample } \\
\text { Mill A: }\end{array}$} & \multicolumn{3}{|c|}{ Uranium Content } \\
\hline & $\begin{array}{l}\text { Number } \\
\text { of } \\
\text { Samples }\end{array}$ & $\begin{array}{c}\text { Percent } \\
\text { of } \\
\text { Implanted } \\
\text { Uranium } \\
\text { (Mean }+ \text { S.E.M.) }\end{array}$ & $\begin{array}{l}\text { Concentration, } \\
\mu g \text { U/g } \\
\text { (Mean }+ \text { S.E.M.) }\end{array}$ \\
\hline Kidney & 21 & $3.2 \pm 0.5^{\mathrm{a}}$ & $34 \pm 5^{a}$ \\
\hline Femur & 20 & $0.90 \pm 0.07^{b}$ & $9.7 \pm 0.84^{b}$ \\
\hline Urine & 41 & $2.16 \pm 0.40^{C}$ & \\
\hline \multicolumn{4}{|l|}{ Mill D: } \\
\hline Kidney & 21 & $1.4 \pm 0.2$ & $14 \pm 3$ \\
\hline Femur & 24 & $0.25 \pm 0.02$ & $2.1 \pm 0.16$ \\
\hline Urine & 25 & $0.65 \pm 0.15$ & \\
\hline \multicolumn{4}{|c|}{$\begin{array}{l}{ }^{a} \text { Significantly different from } M+11 D \text { value }(p<0.005) \text {. } \\
{ }^{b} \text { Significantly different from } M 111 D \text { value }(p<0.0001) \text {. } \\
{ }^{C} \text { Significantly different from } M 111 D \text { value }(p=0.01) \text {. }\end{array}$} \\
\hline
\end{tabular}

Figure 2.4 presents a comparison of the clearance of uranium from the implant site to clearance of uranium from the lungs of rats during the first 35 days after inhalation exposure to the same two yellowcake samples (Ref. 2.1) Urantum clearance from the wound site was more rapid than f:om lung for both yellowcake materials. Retention functions for the curves are listed in Table 2.1.

Figure 2.5 compares retention curves (Eq. 2) fitted to whole-body retention data for rats housed in polycarbonate cages and sacrificed at times from 8 to 16 days after implantation with Mill A yellowcake at a dose of $10 \mathrm{mg} \mathrm{U} / \mathrm{kg}$ with rats implanted at 1 or $3 \mathrm{mg} U / \mathrm{kg}$. Whole-body retention functions for rats implanted with $m i 11$ A yellowcake at reduced dose levels $(1 \mathrm{or} 3 \mathrm{mg}$ $U / \mathrm{kg})$ were not significantly different $(p=0.3)$ from those for rats implanted with Mill $A$ yellowcake at a dose of $10 \mathrm{mg} \mathrm{U} / \mathrm{kg}$. Thus, reduction in uranium dose did not significantly alter uranium clearance rates.

\section{DISCUSSION}

Both whole-body and wound-site uranium clearance half-times were significantly shorter for rats implanted with Mill A yellowcake than for those implanted with Mill 0 yellowcake 

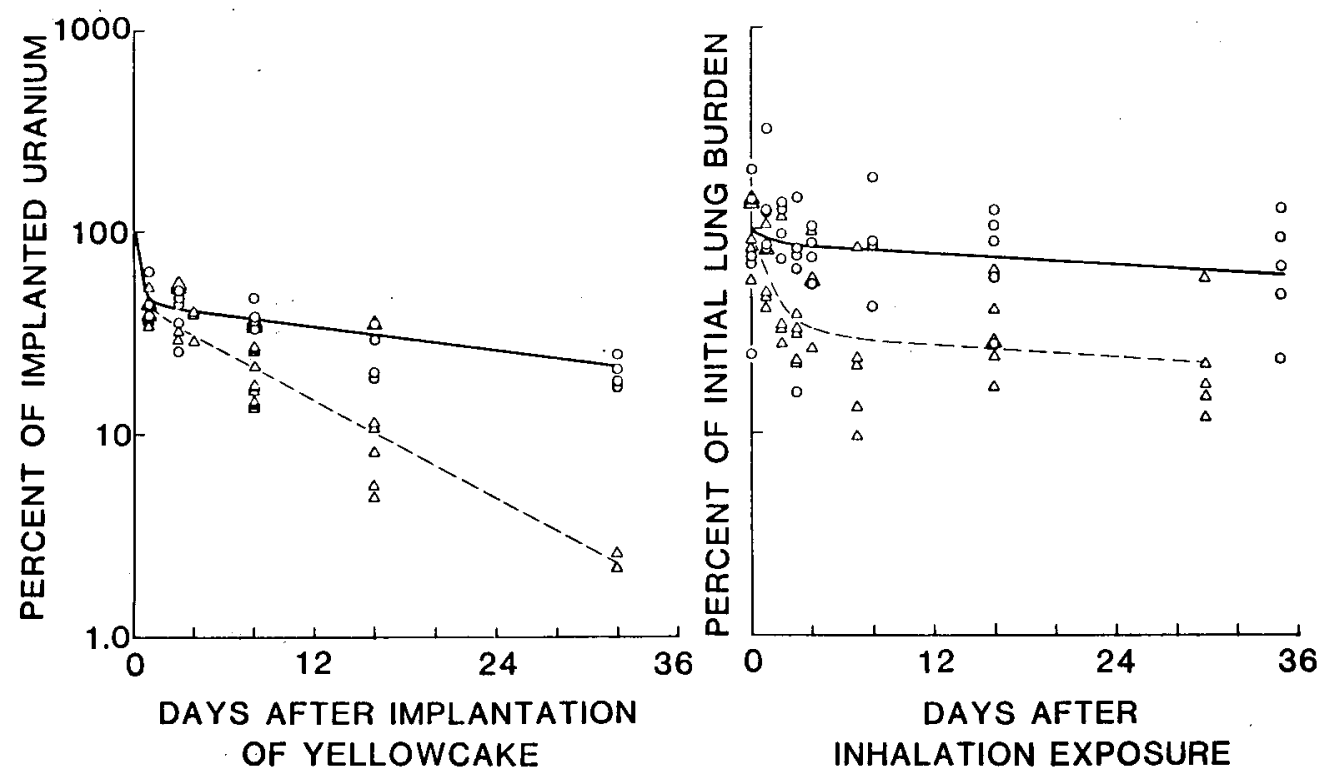

Figure 2.4. Comparison of clearance of uranium from the implant-site of rats receiving subcutaneous implants of yellowcake to uranium clearance from lung in rats exposed to yellowcake powder by inhalation (Ref. 2.1).

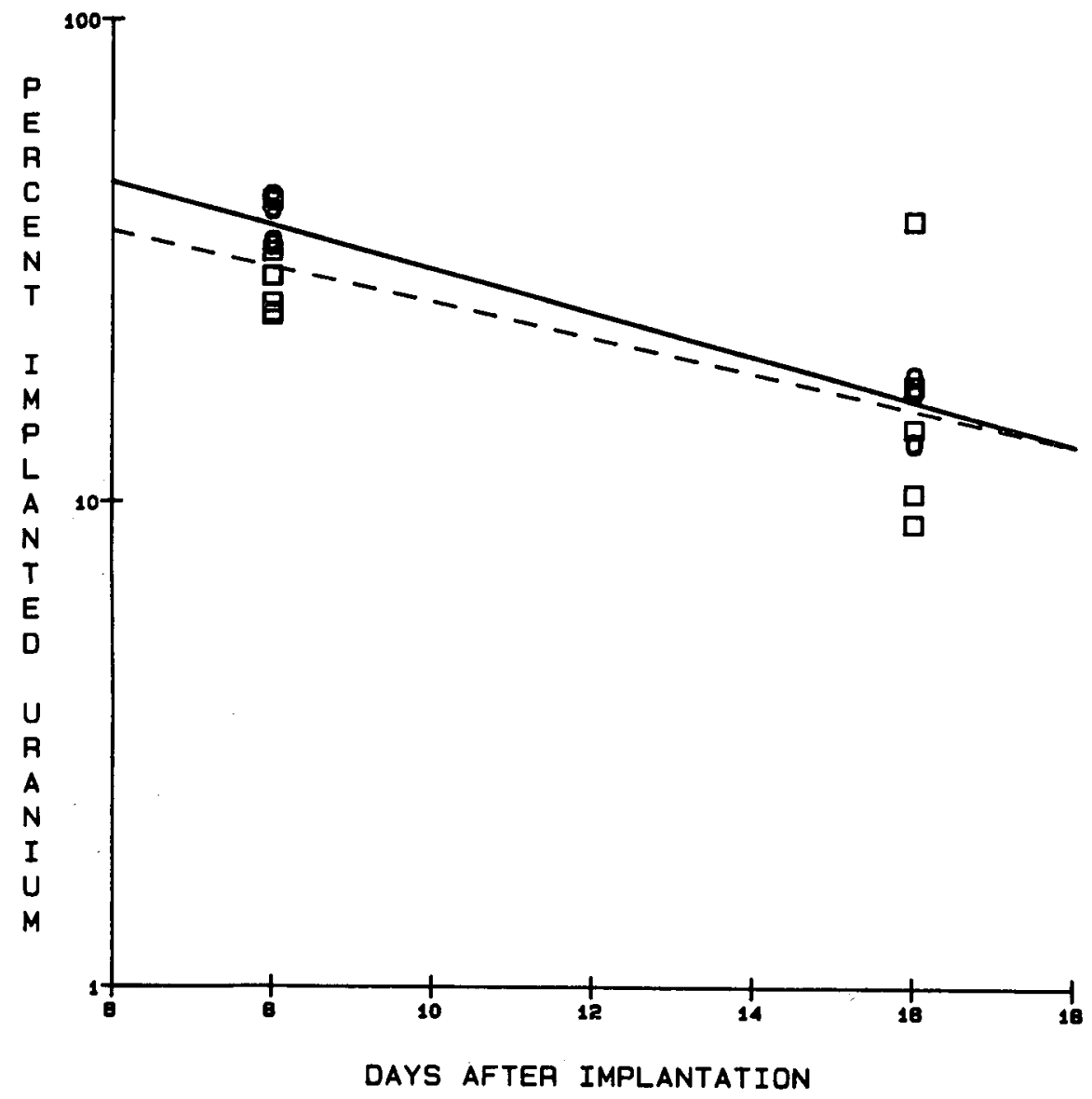

Figure 2.5. Whole-body uranium retention curves for rats receiving implants of Mill A yellowcake at a dose of $10 \mathrm{mg} / \mathrm{kg}$ (solid $1 \mathrm{ine}$ ) or at reduced doses of 1 or $3 \mathrm{mg} / \mathrm{kg}$ (dashed $1 \mathrm{ine}$ ). 
$(p<0.005)$. However, the differences between the retention functions for the two materials were due entirely to the second components (Table 2.1). Retention half-times for the first components of the retention functions were not significantly different for the two materials.

Excretion of uranium in urine and translocation of uranium to kidney and bone was significantly greater $(D<0.01)$ in rats implanted with Mill A yellowcake than in those implanted with Mill $D$ material. Hence, retention and translocation of the implanted uranium depended upon the chemical composition and thus the solubility of the implanted material. However, the clearance rates could not be quantitatively predicted from the chemical composition of the two yellowcake samples. Lung clearance of uranium in rats exposed to aerosols of the two yellowcake samples used in this study were both quantitatively and qualitatively related to the chemical composition and in vitro solubility of the yellowcake samples in an earlier work (Ref. 2.1). Uranium clearance from the wound site of rats implanted with either yellowcake sample was more rapid than the lung clearance rates for rats exposed to these yellowcake aerosols by inhalation.

The difference between clearance of uranium from wounds and from lung may be related to the clearance mechanisms involved. Clearance from a wound occurs mechanically by drainage and phagocytosis and nonmechanically by dissolution and translocation. Clearance from the respiratory tract occurs mechanically (mucociliary action and phagocytos is by pulmonary macrophages) and by dissolution. The level of phagocytic activity - clearing material from a wound may or may not be greater in the rat than the activity of pulmonary macrophages clearing material from a healthy rat lung. It is not known whether the rate of dissolution of uranium deposited in muscle tissue differs greatly from the rate of dissolution of uranium in lung.

Data presented above indicate that there is a qualitative correlation between the amount of uranium retained at the wound site and the content of insoluble $\mathrm{U}_{3} \mathrm{O}_{8}$ in the implanted yellowcake. However, the key question is whether the internal uptake and retention of uranium reflect the chemical composition and relative solubility of the implanted yellowcake. Results reported here indicate there was greater translocation of uranium to kidney and bone in rats implanted with the more soluble yellowcake sample. However, data on the clearance of uranium from the wound site could not be quantitatively related to the $A D U$ and $U_{3} 0_{8}$ composition of the implanted yellowcake or the in vitro dissolution data from the same yellowcake samples. Perhaps mechanical clearance rates from the wound site may have overwhelmed the effects of the differences in chemical composition and relative solubilities of the two materials.

Animal data presented in this paper indicate that wounds contaminated with yellowcake may represent a significant route of entry of uranium into the body. Those responsible for the protection of the health and safety of uranium mill workers should be aware of this potential risk.

\section{REFERENCES}

2.1. E. G. Damon, A. F. Eidson, F. F. Hahn, W. C. Griffith, Jr., and R. A. Guilmette, "Comparison of Early Lung clearance of Yellowcake Aerosols in Rats with In Vitro Dissolution and Infrared Analys is," Health Phys., 1983 (in press).

2.2. J. A. Orcutt, "The Toxicology of Compounds of Uranium Following Application to the Skin," The Pharmacology and Toxtcology of Uranium Compounds, (C. Voegtlin and H.C. Hodge, eds.), pp. 377-414, New York (McGraw-H111), 1949.

2.3. A. F. Eidson and J. A. Mewhinney, "In Vitro Solubility of Yellowcake Samples from Four Uranium Mills and the Implications for Bioassay Interpretations," Health Phys. 39: 893-902, 1980.

2.4 F. L. Haven and H. C. Hodge, "Toxicity Following the Parenteral Administration of Certain Soluble Uranium Compounds," Pharmacology and Toxicology of Uranium Compounds, Chapter 6, (C. voegt 7 in and H. C. Hodge, eds.), DP. 281-308, McGraw-H111 Book Company, Inc., New York. 1949. 
2.5. E. G. Damon, A. F. Eidson, and F. F. Hahn, "Acute Uranium Toxicity Resulting from Subcutaneous Implantation of Soluble Yellowcake Powder in Fischer-344 Rats," Blological Characterization of Radiation Exposure and Dose Estimates for Inhaled Urantum Milling Effluents, Annual Progress Report, Apri1 1980-March 1981, NUREG/CR-2539, LMF-94 Springfield, VA 22161 , pp. 32-37, 1982.

2.6. M. Ralston, "Derivative-Free Nonlinear Regression," BMDP Statistical Software (W. J. Dixon ch.ed.), pp. 305-314, Berkley (Univ. Calif. Press), 1981. 


\section{EFFECT OF ANIMAL CAGING ON NEPHROTOXIC RESPONSE OF RATS TO URANIUM}

Abstract - Urantum mill workers may be exposed to urantum compounds by tnhalation, 1ngestion, wound contamination, or by absorption from eyes or mucous membranes. Rats are currently being used in studies of the translocation and retention of uranium from wounds contaminated with yellowcake (see paper no. 2, th1s report). Dose-response studies were conducted to assess the effects of two types of cages on the nephrotoxic response of rats to Implanted yellowcake. The $L_{50 / 21}$ days was $6 \mathrm{mg} / \mathrm{kg}(95 \% \mathrm{C} . \mathrm{L} .=3-8 \mathrm{mg} / \mathrm{kg}$ ) for rats housed $1 \mathrm{n}$ metabolism cages beginning on the day of implantation (naive rats). However, rats housed in metabolism cages for 21 days before 1 mplantation (acclimated rats) had an LD $50 / 21$ days of 360 $m g / k \dot{~}(95 \%$ C.L. $=220-650 \mathrm{mg} / \mathrm{kg})$, which was the same value obtalned for rats housed continuously in polycarbonate cages. This significant difference (P<0.01) in response of "natve" rats compared to response of "acclimated" rats was related to a stgniflcantly lower water consumption by the naive rats.

Rats are being used as an animal model to study the translocation and retention of uranium from wounds contaminated with yellowcake (see paper no. 2, this report). Rats are usually housed in two types of cages during such studies. All rats are reared and housed in polycarbonate cages, but selected rats are placed in stainless steel metabolism cages with wire-mesh bottoms when excreta are collected. Response of rats to uranium toxicity may be affected by environmental factors related to the type of animal caging used. For example, as noted in paper no. 2 of this report, Fischer-344 rats reared in polycarbonate cages, then housed in metabolism cages immediately after subcutaneous implantation of yellowcake (10 mg/kg body weight) consisting of $\sim 82 \%$ ammonium diuranate (ADU) and $\sim 18 \% \mathrm{U}_{3} \mathrm{O}_{8}$, died from uranium toxicity. Identically exposed rats maintained in polycarbonate cages showed no overt toxic effects. This paper presents results of studies of the effects of two types of animal caging on the acute toxic response of rats to uranium from implanted yellowcake. The purpose of the study is to evaluate environmental factors that may affect the toxicological response of laboratory animals to uranium. Such factors may play a role in determining the toxic response of man to uranium.

The study reported here presents a comparison of the uranium toxicity after implantation with yellowcake in rats housed only in polycarbonate cages (Poly Group), in metabolism cages during a 21-day period of acclimation to these cages prior to implantation with yellowcake (Acclimated Group), or housed in metabolism cages immediately after implantation with yellowcake (Naive Group). Responses of the three groups of rats to uranium toxicity are assessed for correlation with data on food and water consumption, changes in body weight, temperature within the two cage types, and volume of urinary output before and after implantation with yellowcake.

\section{MATERIALS AND METHODS}

\section{Yellowcake Powders}

Two yellowcake powders containing the soluble compound ammonium diuranate (ADU) as the major component were used in these studies. one powder obtained from $M 111$ A contained $\sim 82 \%$ ADU and $\sim 18 \% \mathrm{U}_{3} \mathrm{O}_{8}$ (Ref. 3.1). The second powder, from M $111 \mathrm{~B}$, was composed of $\sim 100 \%$ ADU. 
Animals

One hundred twenty-two male F-344, specific pathogen-free, laboratory-raised rats, 10-12 weeks of age, with initial body weights of $260 \pm 4 \mathrm{~g}$ (mean \pm SEM) were used. Rats were weighed twice weekly froms 3 weeks before implantation until death or sacrifice 21 days after implantation. Rats were fed Lab Blox (Allied Mills, Chicago, IL) and water was provided ad libitum. Water bottles were changed two times a week.

All rats were initially housed individually in polycarbonate cages $(45 \times 25 \times 20 \mathrm{~cm})$ containing a bedding of aspen wood shavings (American Excelsior, 0shkosh, WI). Cage bedding was changed and cages were washed weekly. Animal rooms were maintained on a 12-h light cycle at temperatures of $20-22^{\circ} \mathrm{C}$ and a relative humidity of 40 to $60 \%$. For details of the animal care, see Ref. 3.2.

\section{Experimental Design}

Before implantation with yellowcake, rats were divided into three groups (Table 3.1 ). Group \#1 (47 rats) were housed individually in polycarbonate cages throughout the study. Group \#2 (30 rats) were housed individually in metabolism cages $(18 \times 18 \times 25 \mathrm{~cm}$, Wehman's Manufacturing Co., Timonium, MD) beginning on the day of implantation and until death or sacrifice 21 days after implantation. Group \#3 (45 rats) were housed individually in metabolism cages from 21 days before implantation until death or sacrifice 21 days after implantation.

Water and Food Consumption. Body Weight, Volume of Urinary Output

Water and food consumption were measured dafly for 10 untreated rats in each cage type during a 21-day period of acclimation. Body weights for these rats were measured twice per week during this period. After 21 days of acclimation, the 10 rats in each cage type were divided into three subgroups as follows: Four rats in each cage type were exposed to yellowcake $(10 \mathrm{mg} / \mathrm{kg})$ by subcutaneous implantation, two rats in each cage type were sham-implanted as described below, and four rats in each cage type were retained as cage controls until 34 days of acclimation, at which time they were implanted with yellowcake at a dose of $20 \mathrm{mg} / \mathrm{kg}$. Then, four naive rats were implanted with yellowcake at a dose of $10 \mathrm{mg} / \mathrm{kg}$, and 4 naive controls were sham-implanted. Water consumption and volume of urinary output (measured for the rats in metabolism cages, Groups \#2 \& \#3) were measured daily for rats in these subgroups from the day of implantation until death or sacrifice 21 days after implantation.

\section{Room and Cage Temperature Measurements}

The temperature in the animal room and in two cages of each type was continuously measured by thermistors (\#4404, Omega Engineering Inc., Stanford, CT) and recorded with a five-channel strip-chart recorder (Tigraph 100, Texas Instruments, Lubbock, TX).

\section{Yellowcake Implantations}

Rats were subcutaneously implanted with Mill A or Mill B yellowcake powder at doses listed in Table 3.1 or were surgically sham-implanted. These sham-implanted controls were subjected to the anesthesia and surgical procedures, but no yellowcake was implanted. Anesthesia was induced in rats with a $4 \%$ mixture of halothane (Halocarbon Laboratories, Inc., Hackensack, NJ) vaporized 
Table 3.1.

Effects of Cage Type on Nephrotoxic Response of Rats to Implanted Yellowcake

Group \#1

47 Rats in Polycarbonate Cages:

Yellowcake Powder

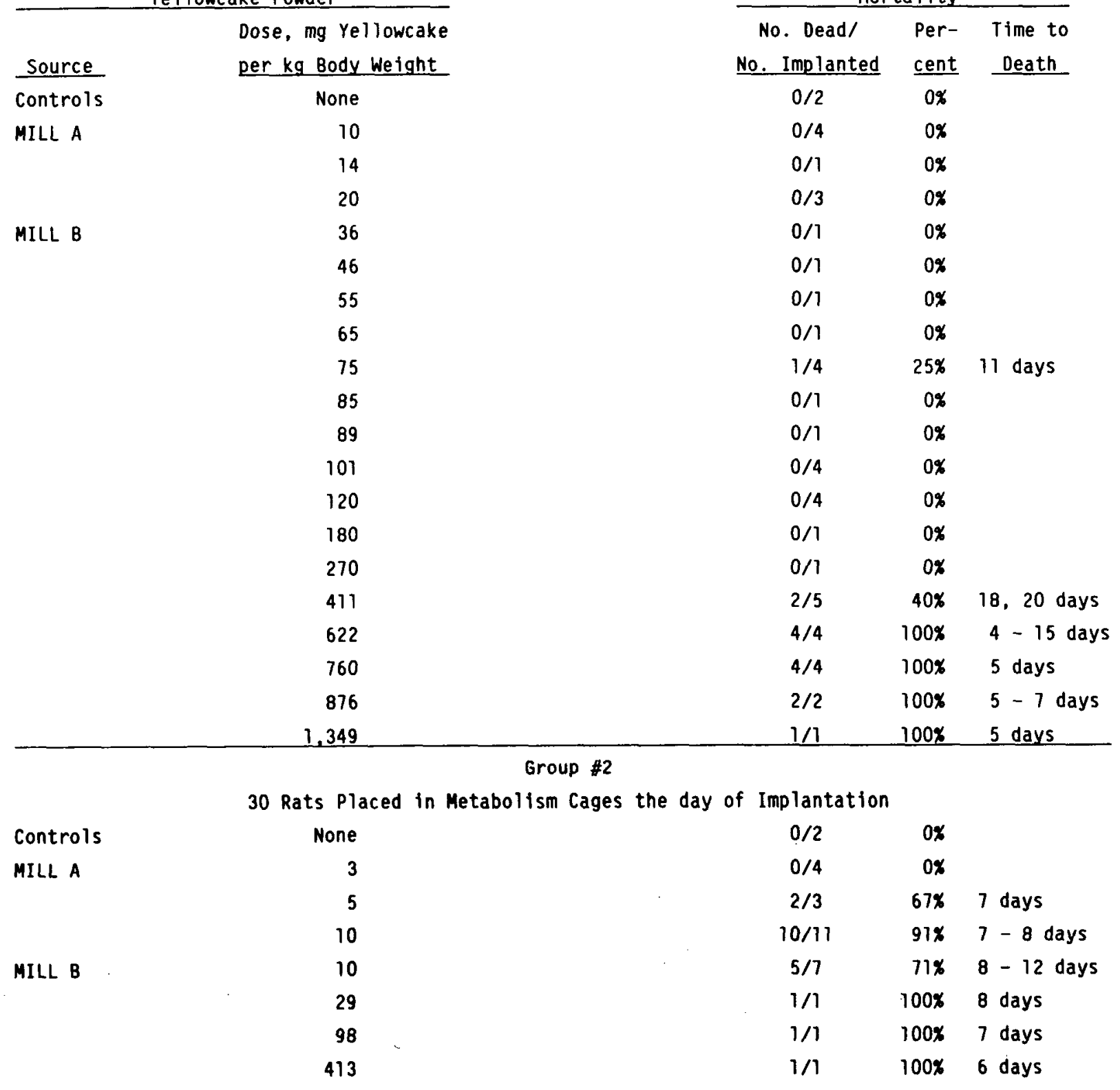


Table 3.1. (Continued)

Group \#3

45 Rats Housed in Metabolism Cages More Than 21 Days Before Implantation

\begin{tabular}{|c|c|c|c|c|}
\hline \multicolumn{2}{|c|}{ Yellowcake Powder } & \multicolumn{3}{|c|}{ Mortality } \\
\hline Source & $\begin{array}{l}\text { Dose, mg Yellowcake } \\
\text { per kg Body Weight }\end{array}$ & $\begin{array}{l}\text { No. Dead/ } \\
\text { No. Implanted } \\
\end{array}$ & $\begin{array}{l}\text { Per- } \\
\text { cent }\end{array}$ & $\begin{array}{l}\text { Time to } \\
\text { Death }\end{array}$ \\
\hline Controls & None & $0 / 2$ & $0 \%$ & \\
\hline \multirow[t]{2}{*}{ MILL A } & 10 & $0 / 4$ & $0 \%$ & \\
\hline & 20 & $0 / 4$ & $0 \%$ & \\
\hline \multirow[t]{12}{*}{ MILL $B$} & 25 & $0 / 4$ & $0 \%$ & \\
\hline & 28 & $1 / 4$ & $25 \%$ & 13 days \\
\hline & 46 & $0 / 1$ & $0 \%$ & \\
\hline & 52 & $1 / 4$ & $25 \%$ & 10 days \\
\hline & 66 & $0 / 1$ & $0 x$ & \\
\hline & 75 & $0 / 1$ & $0 \%$ & \\
\hline & 121 & $0 / 1$ & $0 \%$ & \\
\hline & 411 & $0 / 1$ & $22 \%$ & 11 - 14 days \\
\hline & 620 & $2 / 9$ & $50 \%$ & 5 - 7 days \\
\hline & 760 & $4 / 4$ & $100 x$ & 6 - 11 days \\
\hline & 881 & $1 / 1$ & $100 \%$ & 6 days \\
\hline & 1,350 & $1 / 1$ & $100 \%$ & 4 days \\
\hline
\end{tabular}

in $95 \% \mathrm{O}_{2}$ at a flow rate of $0.6 \mathrm{~L} / \mathrm{min}$ and then malntained with $2 \%$ halothane via a face mask. The hair was clipped from the dorsal thoracic area and a $1-\mathrm{cm}$ long incision was made on the dorsal midline between the scapulae. The dorsal midline was chosen for the implant to prevent the rat from removing the sutures during grooming. The yellowcake dose was subcutaneously implanted, and the skin was sutured with VETAFIL BENGENe ( $S$. Jackson, Inc., Washington, DC). The incision was sprayed with Aeroplaste spray-on plastic dressing (Parke-Davis and Co., Greenwood, SC).

Rats were observed dafly for morbldity or mortality through 21 days after implantation. Surviving rats were sacrificed by an intraperitoneal injection of $1 \mathrm{ml}$ of euthanasia solution (T-61, National Laboratories Corp., Somerville, NJ) administered 21 days after implantation. Necropsies were performed on all rats, thoracic and abdominal viscera were examined grossly, and photographs were taken of the kidneys. Kidneys were assayed for uranium content by fluorometric procedures (Ref. 3.3). A section of kidney from each rat was fixed in 10\%, neutral-buffered formalin, embedded in paraffin, sectioned at $6 \mu \mathrm{m}$, stained with hematoxylin and eosin, and examined by light microscope for histopathological alterations.

\section{Analysis of Data}

Dose-response data for the three groups of rats (Table 3.1) were analyzed by probit analysis of the lethality data (Ref. 3.4). The following probit equation was used for analysis of the mortality data:

$$
y=a+b \log x
$$


where $y=$ mortality at 21 days expressed in probit units, $a=$ the intercept constant, $b=$ the s:lope constant, and $x=$ the implanted dose of yellowcake (mg yellowcake/kg of body weight). The $\mathrm{LD}_{50 / 21}$ days and associated $95 \%$ confidence limits $(\mathrm{CL})$ were derived from the probit regressions and 95\% fiducials (Ref. 3.4).

Food consumption, water consumption, and changes in body weight of rats in the three groups (Table 3.1) were compared by analyses of variance, and significance of differences between groups was determined by F-tests or by the Student's $\underline{t}$-test (Ref. 3.5). Differences were considered to be significant if $p<0.05$.

\section{RESULTS}

\section{Mortality}

Table 3.1 presents mortality data for rats in polycarbonate cages (Group \#1), naive rats in metabolism cages (Group \#2), or acclimated rats in metabolism cages (Group \#3). The LD $50 / 21$ days $(6 \mathrm{mg} / \mathrm{kg}$ with $95 \% \mathrm{CL}$ of $3-8 \mathrm{mg} / \mathrm{kg}$ ) for naive rats housed in metabolism cages was significantly lower than for rats housed in polycarbonate cages $\left(L_{50}=342 \mathrm{mg} / \mathrm{kg}\right.$ with $95 \% \mathrm{CL}$ of $192-635 \mathrm{mg} / \mathrm{kg})$ or for acclimated rats housed in metabolism cages $\left(L D_{50}=444 \mathrm{mg} / \mathrm{kg}\right.$ with $95 \% \mathrm{CL}$ of 199-2047 $\mathrm{mg} / \mathrm{kg})$. The $\mathrm{LD}_{50 / 21}$ days value for rats housed in polycarbonate cages was not significantly different from the $\mathrm{LD}_{50 / 21}$ days for acclimated rats housed in metabolism cages. Therefore, data for these two groups of rats were combined to obtain the dose response curve labeled "acclimated rats" for comparison to the curve for "naive rats" shown in Figure 3.1 .

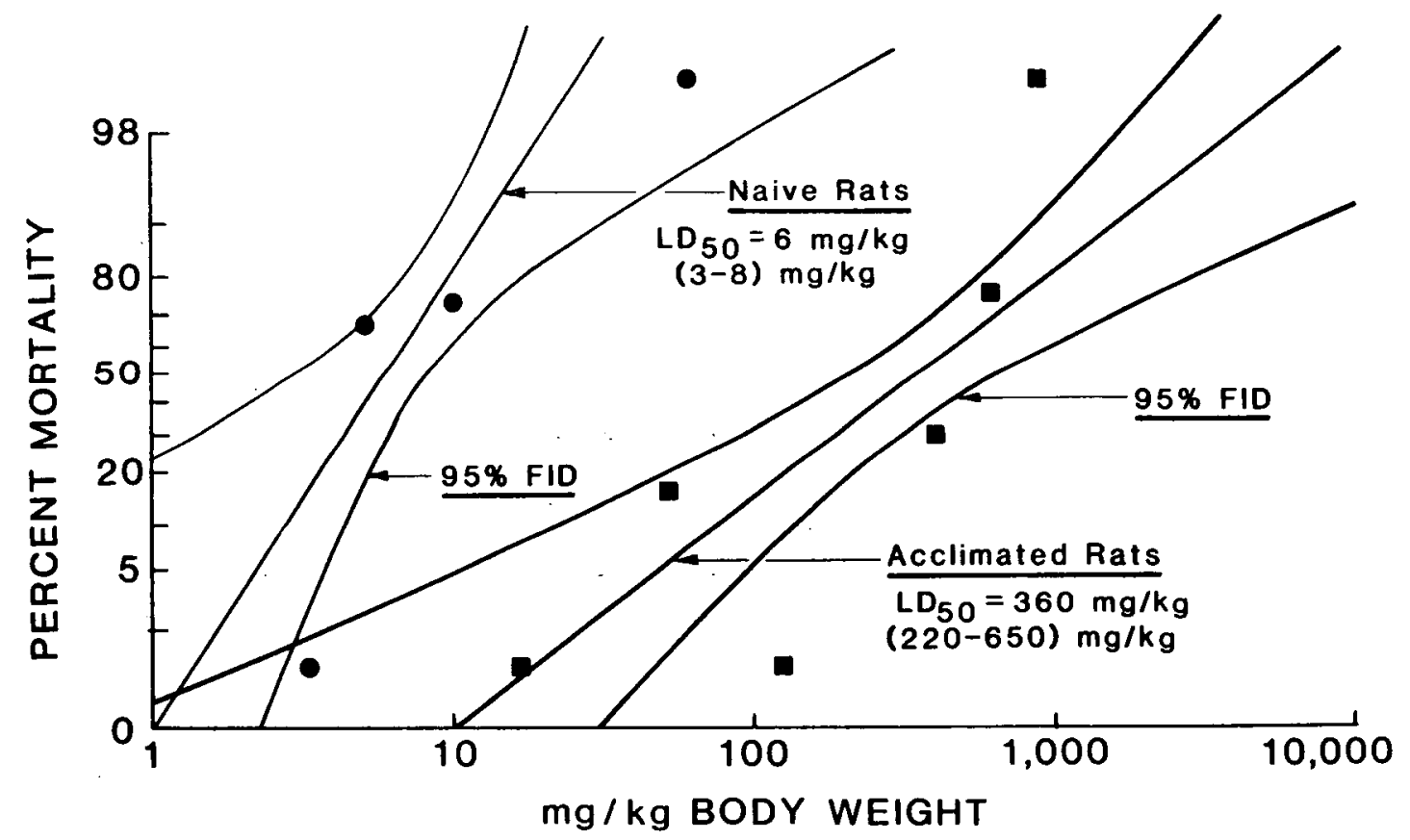

Figure 3.1 Dose-response curves for rats housed in metabolism cages beginning on the day of yellowcake implantation (Naive Rats) or for rats housed in polycarbonate cages or in metabolism cages beginning 21 days before yellowcake implantation (Acclimated Rats). L050 values (and 95\% confidence 1 imits) are for 21 -day mortality. 
Body Weight, Water, and Food Consumption

Figure 3.2 summarizes the body weight data for untreated rats housed in metabolism cages compared to those housed in polycarbonate cages. The figure shows changes in mean body weight for 10 rats in each group through 21 days after the rats were first placed in metabolism cages. At the end of 21 days, six rats from each group were removed from this phase of the study for use in initiation of the dose-response phase of the study. Body weight data shown in the figure for days 21-34 are for four rats in each group. Rats placed in metabolism cages initially lost weight, and the ultimate gain in body weight for these rats was significantly lower than for those housed in polycarbonate cages throughout the period of observations.

Figure 3.3 shows water consumption for the two groups of untreated rats. Rats in metabolism cages drank significantly less water than those housed in polycarbonate cages throughout the observations. Because of the increasing difference in body weight for the two groups of rats (Figure 3.2), water consumption was normalized to body weight. When this was done, the normalized water consumption of the two groups was not significantly different after day 5 .

Food consumption for rats housed in metabolism cages initially was less than that of rats housed in polycarbonate cages, but by day 3 food consumption for the two groups was not significantly different. However, even though food consumption was equal for the two groups of rats from day 3 throughout the period of observations, rats in metabolism cages did not gain weight as fast as those housed in polycarbonate cages. Figure 3.4 shows food consumption normalized to body weight ( $\mathrm{g}$ of food $/ \mathrm{kg}$ of body weight) for the two groups of rats.

Figure 3.5 summarizes the water consumption data for four rats in each group through 21 days after implantation with yellowcake at a dose of $10 \mathrm{mg} / \mathrm{kg}$. The naive rats housed in metabolism cages drank significantly less water than acclimated rats or rats housed in polycarbonate cages until day 8 after implantation. Two of these four rats died with signs of uranium nephrotoxicity 8 or 10 days after implantation. Data beyond day 10 in this group are for the two surviving rats. None of the rats in the other two groups implanted at this dose level $(10 \mathrm{mg} / \mathrm{kg}) \mathrm{died}$. All three groups of rats drank more water after implantation with yellowcake. Water consumption in the surviving rats reached a peak at about day 8 or 9 after implantation.

Figure 3.6 shows the volume of urine excreted by surviving rats during the 21 -day period after implantation for four naive rats, and four acclimated rats implanted with $10 \mathrm{mg}$ of yellowcake/kg and their sham-implanted controls. This figure also shows the volume of urinary output for four acclimated rats implanted with $20 \mathrm{mg}$ of yellowcake/kg. Urinary output by all of the treated rats increased significantly $(P<0.001)$ above that of the sham-implanted controls during the first 2 weeks after implantation. Urinary output by acclimated rats implanted with yellowcake at a dose of $10 \mathrm{mg} . \mathrm{kg}$ was significantly greater than that of naive rats implanted at this same dose level. However, the volume of urine excreted by naive rats surviving longer than 8 days rose above that of the acclimated rats during the 10- to 18-day period after implantation. Urinary output of acclimated rats implanted with yellowcake at a dose of $20 \mathrm{mg} / \mathrm{kg}$ was not significantly different from that of rats implanted at a dose of $10 \mathrm{mg} / \mathrm{kg}$.

Reduced tolerance to uranium toxicity exhibited by naive rats housed in metabolism cages was related to reduced water consumption by these rats (Figure 3.5) during the first 4 days after yellowcake implantation, coincident with the peak nephrotoxic effect of the implanted uranium. Rats housed in polycarbonate cages or rats acclimated to metabolism cages for 21 days before yellowcake implantation consumed significantly more water during this time than the naive rats (Figure 3.5). 


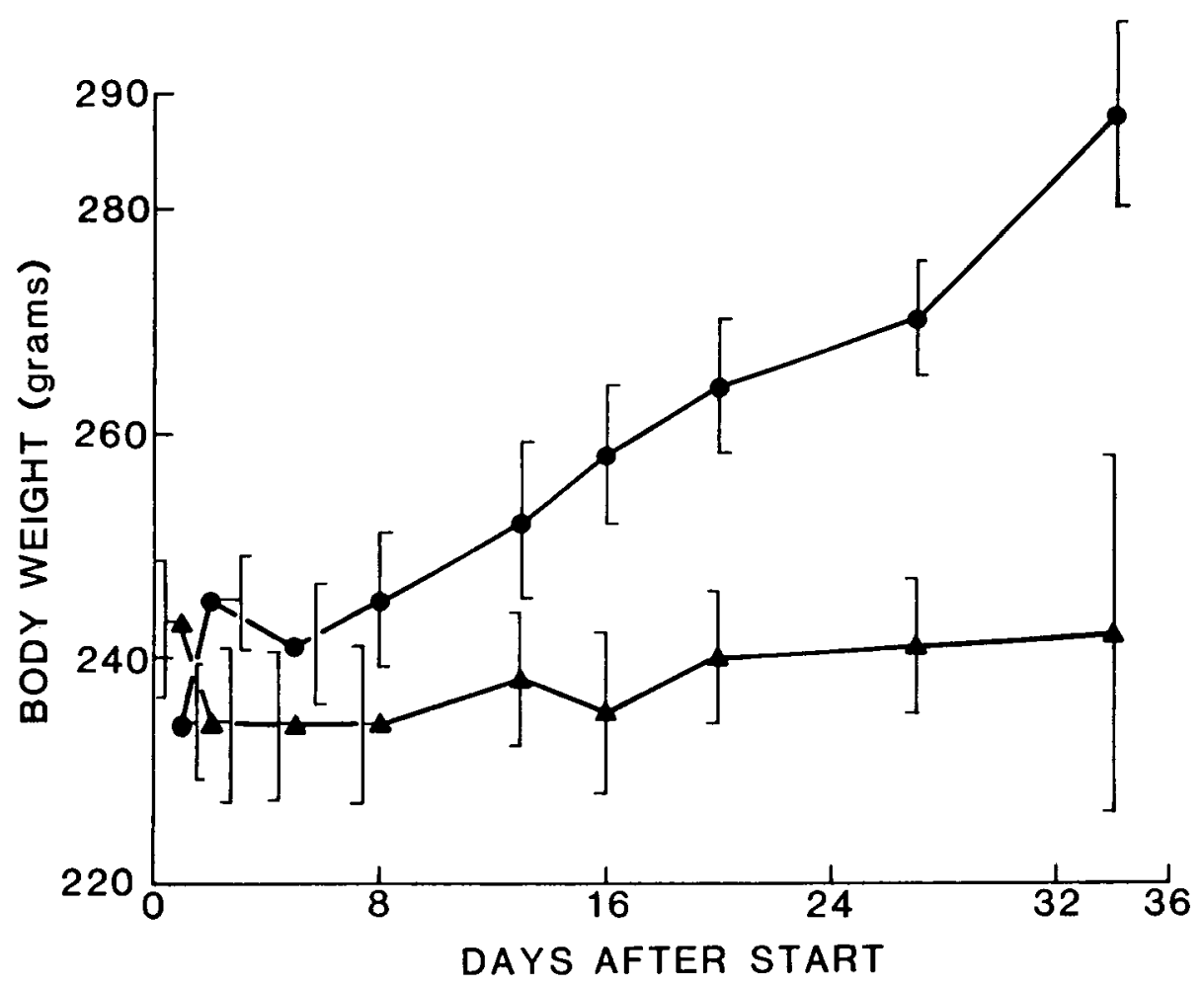

Figure 3.2 Mean body weight of rats housed in metabolism cages (triangles) or in polycarbonate cages (circles). Error bars represent \pm 1 SEM.

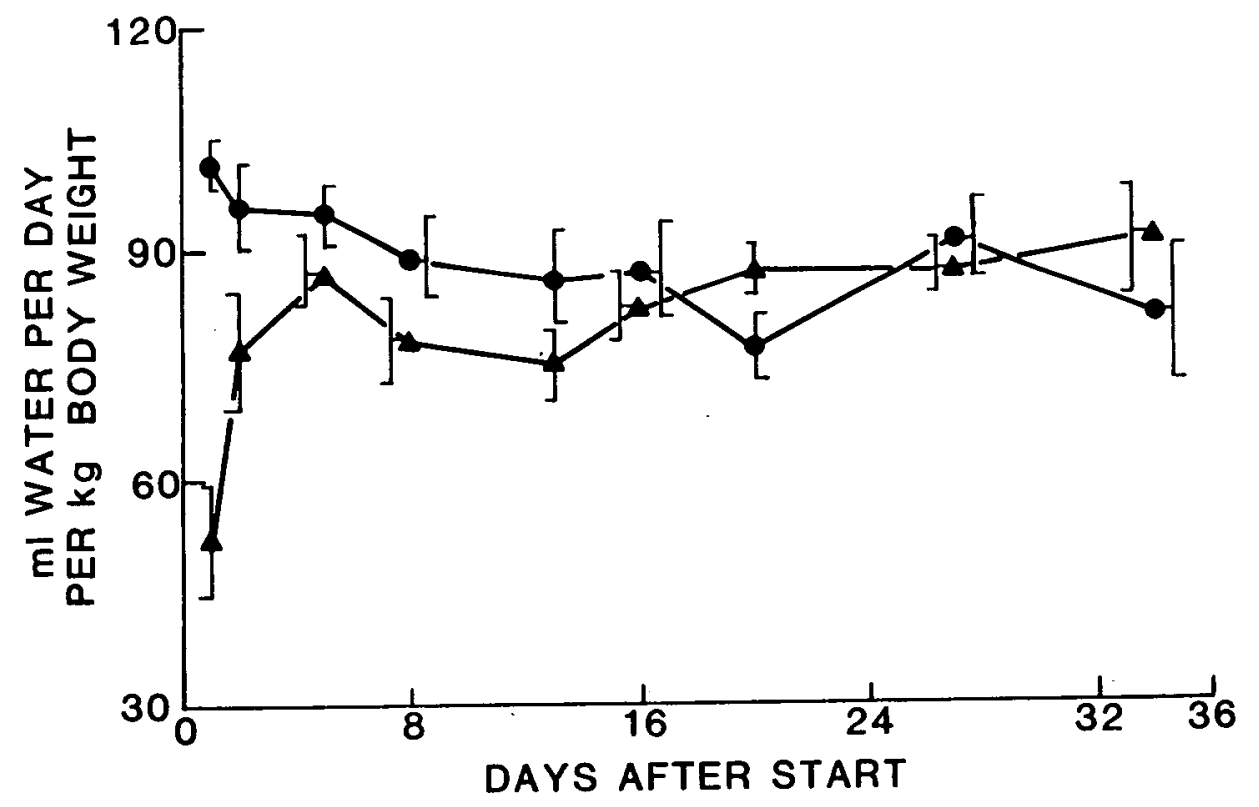

Figure 3.3 Mean water consumption (ml/kg body weight) for rats housed in metabolism cages (triangles) or in polycarbonate cages (circles). Error bars represent \pm 1 SEM. 


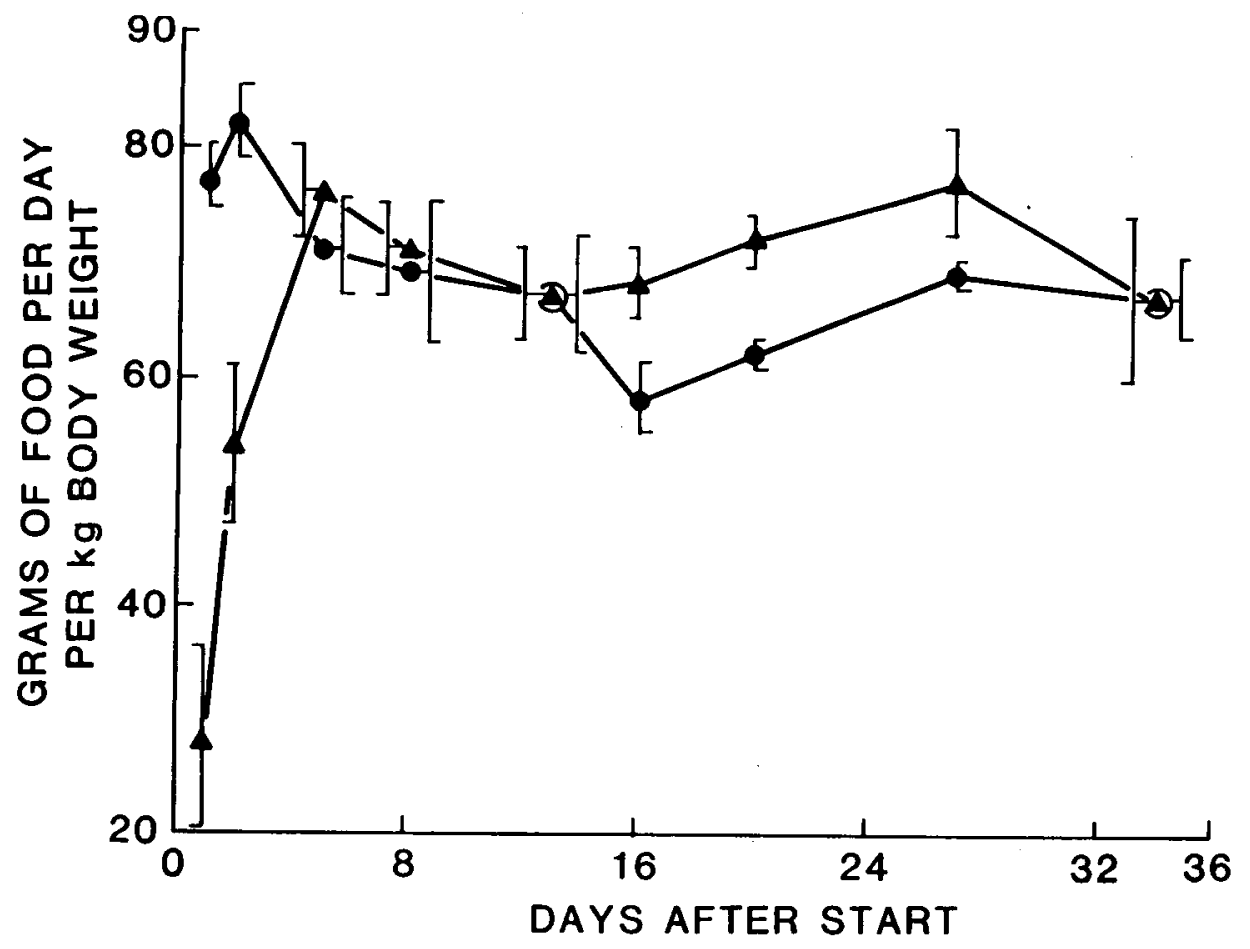

Figure 3.4 Mean food consumption ( $\mathrm{g} / \mathrm{kg}$ body weight) for rats housed in metabolism cages (triangles) or in polycarbonate cages (circles). Error bars represent \pm 1 SEM.

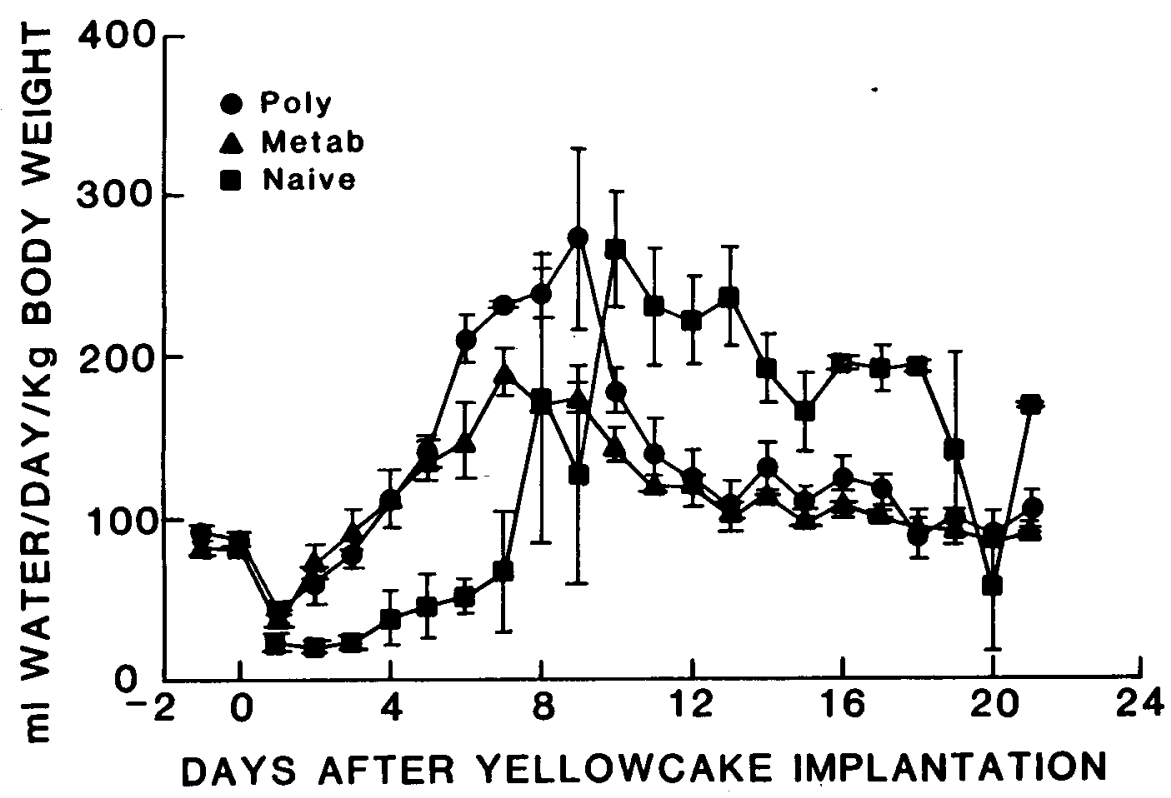

Figure 3.5 Mean water consumption by rats implanted with $10 \mathrm{mg}$ yellowcake/kg body weight. The line with data points as squares is for naive rats housed in metabolism cages, the line with data points as triangles is for rats "acclimated" to metabolism cages, and the iline with points as circles is for rats housed in polycarbonate cages. Error bars represent \pm 1 SEM. 


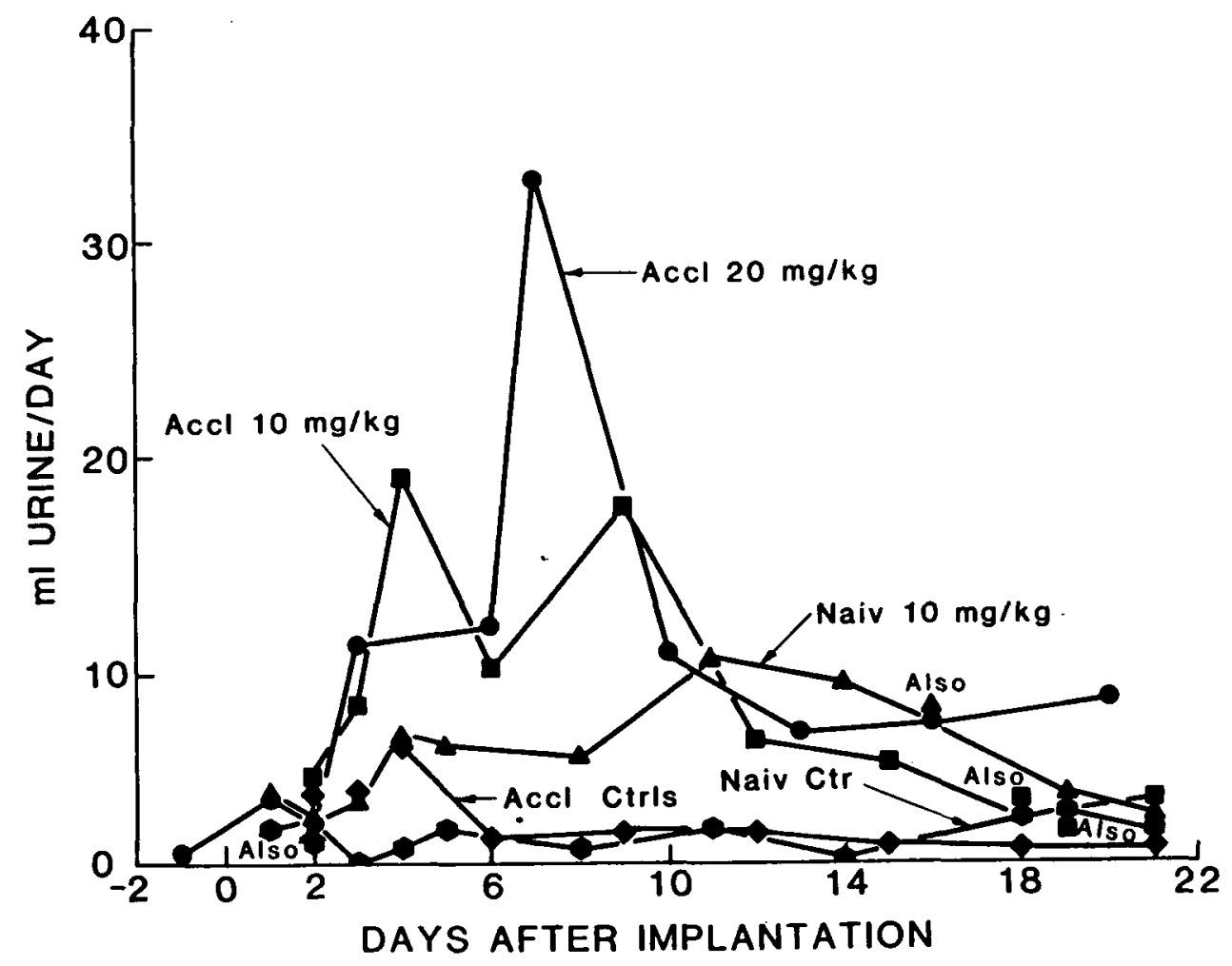

Figure 3.6 Volume of urinary output by rats after subcutaneous implantation with yellowcake.

Uranium Concentration in Kidney

The concentration of uranium in the kidneys $(72 \pm 18 \mu \mathrm{g} / \mathrm{g})$ of four naive rats that died 8 days after implantation with yellowcake at a dose of $10 \mathrm{mg} / \mathrm{kg}$ was significantly higher than that of five surviving rats $(16 \pm 4 \mu \mathrm{g} / \mathrm{g})$ housed in polycarbonate cages and sacrificed 8 days after implantation with yellowcake at this same dose level (the latter were rats in the wound retention study described in paper no. 2 of this report).

Animal Room Temperature and Cage Temperature

The mean room temperature (during 24 days) and mean temperature in each of two metabolism cages and two polycarbonate cages are plotted at 4- $h$ intervals through a 24-h cycle in Figure 3.7. Temperature in the polycarbonate cages was significantly lower than the temperature in metabolism cages throughout the 24-h cycle.

\section{Histopathological Observations}

Kidneys of naive rats that died 8 days after implantation with yellowcake at a dose of 10 $\mathrm{mg} / \mathrm{kg}$ appeared pale, with mottled reddish coloration and yellowish speckling (Figure 3.8 ). Widespread massive necrosis of tubular epthellal cells was present, and it involved essentially all tubules and the proximal and distal portion of each individual tubule. Nearly all tubular epithelial cells were necrotic and sloughed. Massive casts of necrotic cells, calcified debris, and protein filled the tubules. The glomeruli were relatively spared. Rats in the wound retention study (See paper no. 2 in this report) that were killed at 16 days after implantation 


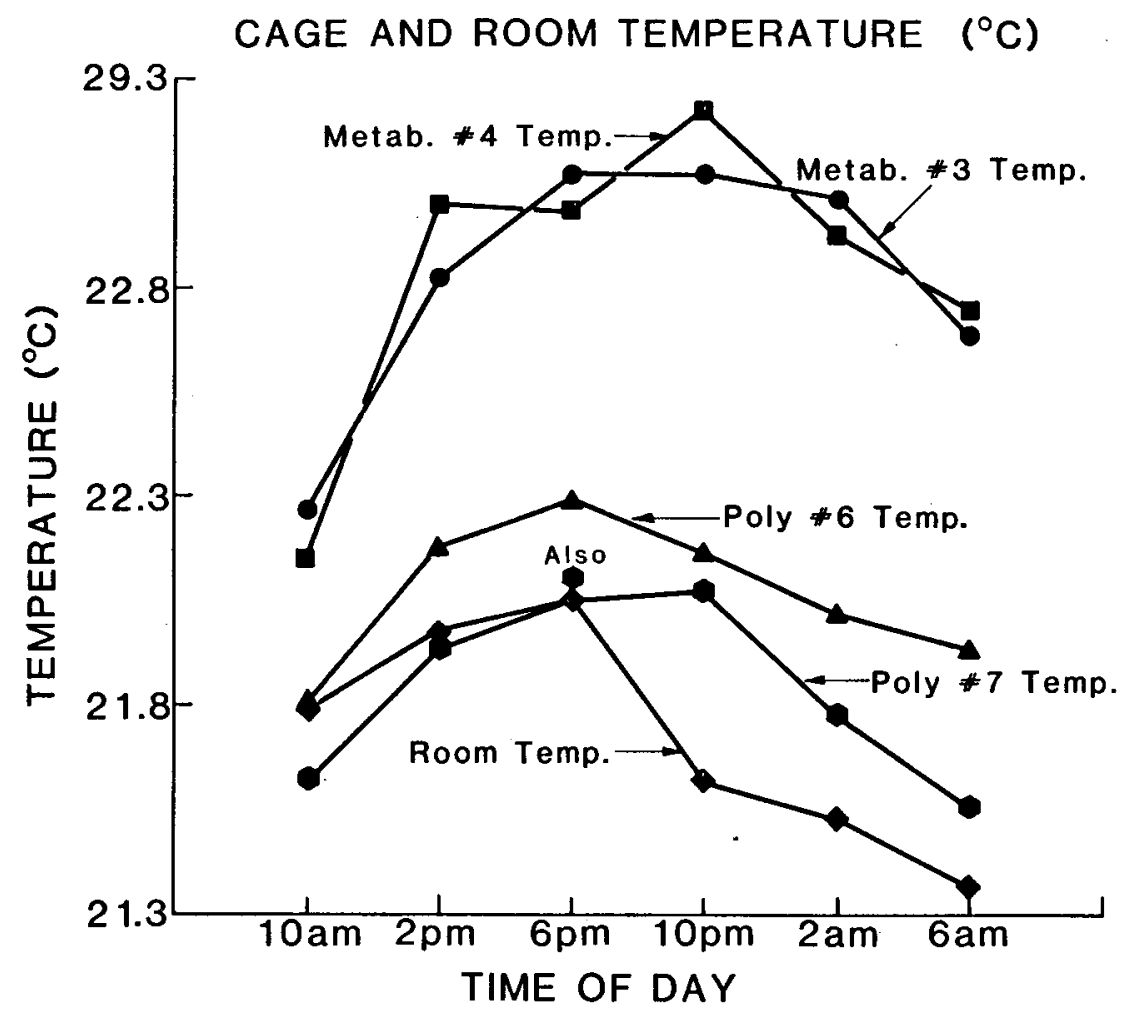

Figure 3.7 Comparison of animal room temperature and temperatures recorded in polycarbonate cages or in metabolism cages during a $24-h$ cycle.
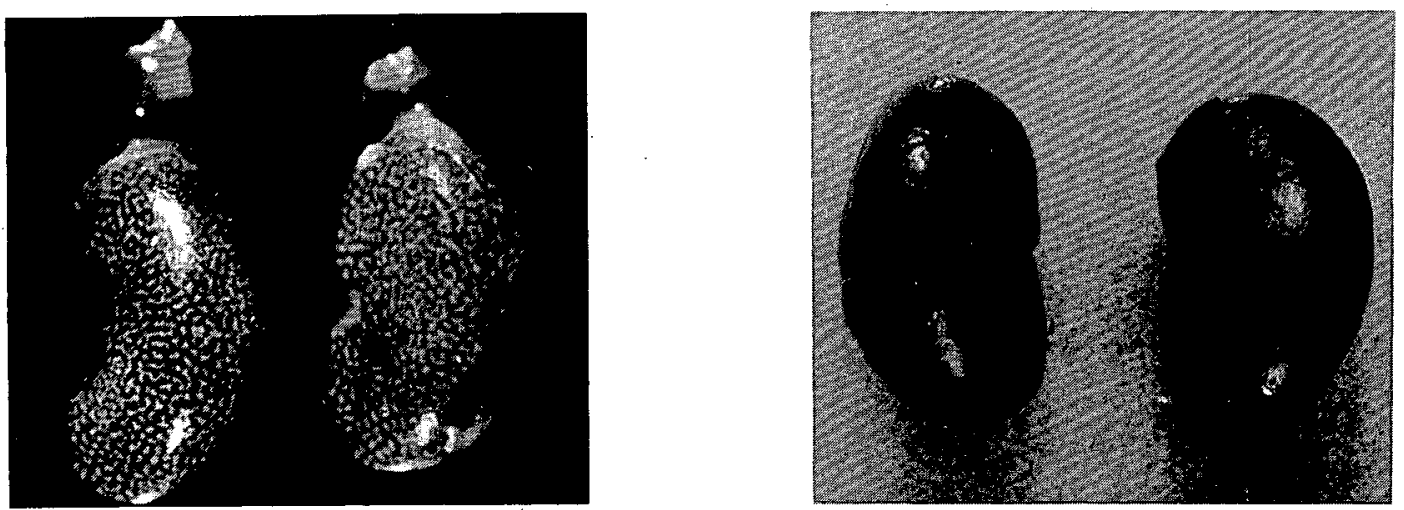

Figure 3.8 Gross appearance of kidneys of naive rat that died 8 days after implantation of yellowcake at a dose of $10 \mathrm{mg} / \mathrm{kg}$ (left) compared to kidneys of normal rat (right). 
(10 mg/kg) also had tubular necrosis but of a less widespread, severe nature. In addition, many 'tubules were lined by small flattened basophilic immature epithelial cells. It appeared that these rats had undergone a period of acute tubular necrosis, and repair of tubules had begun. The histopathological changes noted above were generally similar to those reported by Barnett and Metcalf in Voegtlin and Hodge (Ref. 3.6) in their description of the pathological anatomy of the kidney following uranium poisoning.

\section{DISCUSSION}

The histopathological observations noted for rats in these studies that died eight days after implantation with yellowcake were generally similar to those reported by others for rats after oral or parenteral administration of uranyl nitrate (Refs. $3.6-3.12$ ). In earlier studies of toxicity from parenteral administration of soluble uranium compounds to animals, rats were usually housed in wire cages in groups of five or fewer (Refs. 3.6, 3.13). Haven and Hodge reported $L_{50 / 48} \mathrm{hr}$ or $L_{50 / 21}$ days values of $86 \mathrm{mg} / \mathrm{kg}$ or $2.5 \mathrm{mg} / \mathrm{kg}$, respectively, for male Wistar rats housed in wire cages after a single intraperitoneal injection of uranyl nitrate hexahydrate (Ref. 3.13). The $\mathrm{LO}_{50 / 21}$ days value $(6 \mathrm{mg} / \mathrm{kg}$ with $95 \%$ confidence limits of $3-8$ $\mathrm{mg} / \mathrm{kg}$ ) reported here for naive $\mathrm{F}-344$ rats housed in metabolism cages after implantation with yellowcake powder was not significantly different from the 21 -day $L D_{50}$ value cited above.

Orcutt reported an $\mathrm{LD}_{50}$ value of $1 \mathrm{~g} / \mathrm{kg}$ for aqueous solutions of $\mathrm{UO}_{2} \mathrm{~F}_{2}$ or $\mathrm{UO}_{2}\left(\mathrm{NO}_{3}\right)_{2}$ applied to the shaved skin of rats (Ref. 3.14). This is about $10^{3}$ times the $\mathrm{LO}_{50}$ for a single intraperitoneal injection of uranyl nitrate solution and an equal amount above the $\mathrm{LD}_{50}$ value reported here for naive rats housed in metabolism cages after subcutaneous implantation of dry yellowcake with ammonium diuranate as the major ingredient.

Results presented here indicate that rats housed in metabolism cages beginning immediately after subcutaneous implantation with yellowcake were more susceptible to uranium toxicity than rats housed in polycarbonate cages or rats acclimated in metabolism cages for 21 days before yellowcake implantation. Difference in response of the two groups of rats was related to differences in water consumption during the first 8 days after yellowcake implantation.

One might expect the water consumption by rats housed in metabolism cages where the temperatures were higher to be greater than for those housed in polycarbonate cages where the temperatures were lower. However, water consumption by nalve rats placed in metabolism cages was initially lower than that of rats continually housed in polycarbonate cages, even though the temperature within the metabolism cages was higher than the temperature within the polycarbonate cages.

The greater tolerance to uranium toxicity exhibited by rats housed in polycarbonate cages compared to naive rats housed in metabolism cages was related to the lower concentration of uranium in the kidneys of these rats than in the naive rats housed in metabolism cages. The difference in uranium concentration in kidney of the two groups of rats was related to differences in water consumption by rats in these two groups. Water consumption by rats acclimated to metabolism cages was equal to that of rats housed in polycarbonate cages, and the response of these two groups of rats to uranium toxicity was simflar. These findings are similar to those reported by Ryan et al (Ref. 3.7) that increase in fluid intake and urinary output by saline-loaded rats was correlated with reduction in uranyl nitrate-induced acute renal failure. These investigators reported that saline loading (provision of is saline as the sole source of drinking water) afforded protection in rats against the development of acute renal fallure induced by uranyi nitrate (Ref. 3.7). Saline-loaded rats exhibited greater fluid intake and urinary output than rats drinking water at 24 or 48 hrs after intravenous injection with uranyl nitrate 
solution at a dose of $10 \mathrm{mg} / \mathrm{kg}$. Saline loading ameliorated the azotemia but not the renal tubular necrosis or tubular dysfunction that are characteristic of uranium nephrotoxicity. (Ref.s. 3.7 3.9). However. Avasthi et al. (Ref. 3.10) reported that saline loading protected rats' against alterations in both renal function and endothelial cell morphology (as assessed by electron microscopy), whereas sodium depletion in rats after administration of uranyl nitrate $(15 \mathrm{mg} / \mathrm{kg})$ resulted in development of a marked reduction in the glomerular filtration rate and significant alterations in endothelial cell morphology. In saline loaded rats, a lower concentration of uranyl nitrate as a result of increased fluid intake and urinary output may have prevented the cellular injury.

We conclude that rats housed in polycarbonate cages or in metabolism cages after a 21-day period of acclimation exhibited a significantly lower nephrotoxic response to uranium from implanted yellowcake than did naive rats housed in metabolism cages. Greater toxic response of the naive rats to implanted yellowcake was related to reduction in water consumption by these rats compared to those housed in polycarbonate cages or rats housed in metabolism cages after acclimation to this cage type. Difference in water consumption of the two groups of rats may be due to differences in the behavior patterns between the naive rats and those housed in polycarbonate cages. The differences in water consumption could not be related to differences in temperature within the two types of cages.

It has generally been recognized that a period of acclimation must be provided for laboratory animals placed in a new environment before undertaking toxicity studies. However, the time period required for acclimation of rats to metabolism cages has not been determined previously. Data presented here indicate that minimum periods of 3 days or 5 days are required for acclimation in terms of food consumption or water consumption, respectively. However, rate of change of body weight for rats housed in metabolism cages was less than that of rats housed in polycarbonate cages throughout a 34-day period of observation. Therefore, further studies of acclimation of rats to metabolism cages are required to determine the minimum period of acclimation needed for studies involving measurements in changes of body weight of rats housed in these two cage types.

Figure 3.3 shows that water consumption of rats housed in metabolism cages was less than for rats housed in polycarbonate cages until 16 days of acclimation (although the difference was not statistically significant beyond day 5). Therefore, we recommend that in future studies requiring excreta collections, a minimum 21-day acclimation to metabolism cages should be provided before exposure of rats to nephrotoxic test substances. This should provide a measure of assurance that water consumption and nephrotoxic responses of rats in the two cage types will be simflar.

\section{REFERENCES}

3.1 A. F. Eidson and J. A. Mewhinney, "In Vitro Solubility of Yellowcake Samples from Four Uranium Mills and the Implications for Bioassay Interpretations, "Health Physics 39: 893-902.

3.2 H. C. Redman, C. H. Hobbs, and A. H. Rebar, "Survival Distribution of Syrian Hamsters (Mesocricetus auratus, Sch:SYR) Used During 1972-1977," Progress in. Experimental Tumor Research, Vo1. 24, (F. Homburger, ed.), pp. 108-117, Karger, Base1, 1979.

3.3 E. G. Damon, A. F. Eldson, F. F. Hahn, W. C. Griffith, Jr., and R. A. Guilmette, "Comparison of Early Lung Clearance of Yellowcake Aerosols in Rats with In Vitro Dissolution and Infrared Analysis," Health Physics 1983, (in press).

3.4 D. J. Finney, Probit Analysis, 3rd ed. Cambridge Univ. Press, Cambridge, England, 1971.

3.5 M. Ralston, "Derivative-Free Nonlinear Regression," BMDP Statistical Software (W. J. Dixon, ch. ed.), pp. 305-314, Berkeley (Untv. Calif. Press), 1981. 
3.6 C. Voegtilin and H. C. Hodge (eds.): The Pharmacology and Toxicology of Uranium Compounds, National Nuclear Energy Series, Division IV, Vol. 1 and Div. Vi, Vol. 1, PP. 207-236, McGraw-H111 Book Co., Inc., New York, 1949 and 1951.

3.7 R. Ryan, J. S. McNei1, W. Flamenbaum, and R. Nagle (Introduced by Robert J. T. Joy), "Uranyl Nitrate Induced Acute Renal Fallure in the Rat: Effect of Varying Doses and Saline Loading," Proc. Soc. Exp. B101. Med. 143: 289-296, 1973.

3.8 D. P. Haley, "Acute Renal Fallure Induced by Uranyl Nitrate: Structural and Functional Response of Water and Saline Drinking Rats," Doctoral Dissertation. The University of Texas Health Science Center at San Antonio, 1980.

3.9 D. P. Haley, "Morphologic Changes in Uranyl Nitrate-Induced Acute Renal Failure in Salineand Water-Drinking Rats," Lab. Invest. 46: 196-208, 1982.

3.10 P. S. Ataschi, A. P. Evan, and D. Hay, "Glomerular Endothelial Cells in Uranyl NitrateInduced Acute Renal Fallure in Rats," J.Clin. Invest. 65: 121-127, 1980.

3.11 K. A. Goel, V. K. Garg, and Veena Garg, "Histopathology of Kidney of Albino Rat Poisoned with Uranyl Nitrate," Bull. Environ. Contam. Toxicol. 24: 9-12, 1980.

3.12 P. W. Durbin and $\dot{M}$. E. Wrenn, "Metabolism and Effects of Uranium in Animals," Occupational Health Experience with Uranium, (M. E. Wrenn, ed.), ERDA93, pp. 68-129, Arlington, VA, 1975. Available from National Technical Information Service, Springfield, VA 22161.

3.13 F. L. Haven and H. C. Hodge, "Toxicity Following the Parenteral Administration of Certain Soluble Uranium Compounds, "Pharmacology and Toxicology of Uranium Compounds, Chapter 6, (C. Voegtlin and H. C. Hodge, eds.) pp. 281-308, McGraw-Hill book Company, Inc.., New York, 1949.

$3.14 \mathrm{~J}$. A. Orcutt, "The Toxicology of Compounds of Uranium Following Application to the Skin," The Pharmacology-and Toxicology of Uranium Compounds, (Voegtlin C. and Hodge H.C., eds.), PD. 377-414, New York (McGraw-Hi11), 1949. 


\section{TWO-YEAR DOSE PATTERN STUDIES OF INHALED YELLOWCAKE IN THE BEAGLE DOG}

Abstract - Forty-four Beagle dogs were exposed to aerosols generated from yellowcake samples obtained from two uranium mills. The two materials PRINCIPAL INVESTIGATORS represented two extremes in yellowcake composition A. F. EIdson that occur in industry: one was $100 \%$ ammontum di-

E. G. Damon uranate; the other was $>99 x \mathrm{U}_{3} \mathrm{O}_{8}$. The aerosols of the $100 \%$ ammonium diuranate form inhaled by 20 dogs averaged $3.4 \pm 0.5$ microns (mean $\pm I S E$ ) mass median aerodynamic diameter (MMAD), and $1.5 \pm 0.04$ geometric standard deviation (GSD). The average estimated initial lung burden was $130 \pm 9 \mu \mathrm{Hg} / \mathrm{kg}$ body weight. Exposure aerosols of the $>99 \% 0_{3} \circ_{8}$ form tnhaled by the second group of 20 dogs averaged $3.0 \pm 0.3 \mu m$ MHAD and $1.7 \pm 0.1$ GSD. The estimated Initial lung burden for the second group was $140 \pm 7 \mu g \mathrm{U} / \mathrm{kg}$ body welght. Sacrifices are completed through 64 days after exposure for both experiments, and analysis of tissue and excreta samples for urantum content is in progress.

Investigation of the short-term patterns of retention and excretion of inhaled uranium in rats exposed to yellowcake aerosols from two uranium mills has shown that clearance of inhaled yellowcake from the lung depends, in part, on the yellowcake solubility in body fluids (Ref. 4.1 ). The translocation to other tissues (e.g., bone) and excretion through the kidney also appears to be solubility related.

Experiments were designed to provide data on the long-term pattern of clearance of uranium in beagle dogs exposed by inhalation of two types of yellowcake, a more soluble form and a less soluble form. Aerosols of the two yellowcake forms obtained from operating mills were generated directly from powders for nose-only inhalation exposures. The results of this study in dogs will be compared with the available data on human exposure to $\mathrm{U}_{3} \mathrm{O}_{8}, \mathrm{UO}_{2}$, and to $\mathrm{UO}_{3}(\mathrm{Ref} .4 .2,4.3)$. The objectives of this study are:

(1) to assess the patterns of retention and excretion in dogs of two chemical forms of uranium commonly present in yellowcake aerosols;

(2) to relate the above metabolism of uranium from inhaled yellowcake aerosols to their physical and chemical properties; and

(3) to relate the observed behavior of yellowcake to humans and suggest possible bioassay schemes.

\section{MATERIALS AND METHODS}

Two samples of yellowcake were chosen, based on infrared analys is to represent the extremes of composition observed at uranium mills: one material was $100 x$ ammonium diuranate (a more soluble form); the other was $<1 \times$ ammonium diuranate and $>99 \% \mathrm{U}_{3} 0_{8}$ (a relatively insoluble form; see Paper 1 of this report).

Forty-four beagle dogs, including an equal number of males and females, 2 to 6 years of age were selected. Twenty dogs were exposed to each material, and four were retained as unexposed controls to be used as quality controls for the uranium fluorometry analyses. Exposure aerosols were generated from the dry yellowcake powders using a Devilbiss Model 125 powder generator (Ref. 4.4). 
Aerosol concentration was monitored during exposure by a Model RAM-S nephelometer (GCA Corp.; Bedford, MA) calibrated with aerosols generated from the same yellowcake powder. Calibration aerosols were generated using constant air flow rates and were sampled simultaneously using the nephelometer and membrane filters. The uranium deposited on the membrane filters was determined by reflectance fluorometry (Ref. 4.5), and the aerosol concentration was calculated using the flow rate through the filter and the sampling duration.

The nephelometer was used to monitor the exposure aerosol concentration continuously during each exposure and to allow a more accurate estimate of the amount inhaled by the dog. The breathing frequency and tidal volume of the dog were monitored during exposure using a whole-body plethysmograph (Ref. 4.6). Estimates of the initial lung burden were made using the cumulative volume of air inhaled, the average aerosol concentration, and deposition efficiency of $20 \%$ for the pulmonary compartment of the lung. The aerosol particle size distribution was determined by analysis of the yelloweake deposited on each stage of cascade impactors and fitting a lognormal distribution function to the data.

Because renal toxicity might be caused by inhalation of uranium, blood and urine samples. were collected to monitor renal function. Blood and urine samples were also collected from all dogs before exposure and at sacrifice. Additional samples were collected at 8 and 16 days after exposure and at 90-day intervals thereafter. Blood serum was analyzed for blood urea nitrogen, creatinine, total protein, albumin, calcium, and inorganic phosphate content using a Multistat III microcentrifugal analyzer (Instrumentation Laboratories Co., Lexington, MA). Whole blood was analyzed for hematocrit, hemoglobin, red and white cell counts, and mean cell volume using a Coulter Model $28 \mathrm{I}$ Counter (Coulter Electronics Co., Hialeah, $\mathrm{FL}$ ) and a Coulter hemoglobinometer.

Comparative differential cell counts and platelet estimation tests were included. Standard chemical analyses of urine include: protein, glucose, ketones, urobilinogen, bilirubin, blood and hemoglobin content, specific gravity, and pH. Sediments were analyzed microscopically for cells, casts, and crystals.

Urine, feces, and cage wash water were collected daily from 2 days before exposure until 16 days after exposure, then three dally collections per week were made for 2 weeks. Subsequently, three dafly collections per month were made every other month until 180 days after exposure. After 180 days, three consecutive daily collections of excreta were made at 3 -month intervals until sacrifice.

Dogs are scheduled, for sacrifice at $0.08,2,4,8,32,64$, and 180 days and at 1, 1.5, and 2 years after exposure. Four exposed dogs in each study were not assigned to specific sacrifice groups, but are reserved as replacements in case of deaths during the term of the study. One of the control dogs in each study was sacrificed at 2 days and one will be sacrificed at 2 years to provide quality control data on fluorometric analyses during the study. Selected tissues taken at necropsy for uranium analysis include: blood, skull, turbinates, trachea, lung, kidney, gastrointestinal tract (including esophagus and stomach), liver, spleen, tracheobronchial lymph nodes, femur, and lumbar vertebrae. Tissues taken for histopathological examination include samples of kidney, femur, liver, spleen, lymph nodes, lung, and any lesions observed. Tissues and excreta are analyzed for uranium content by reflectance fluorometry.

\section{RESULTS AND OISCUSSION}

Scheduled sacrifices are complete through one year after exposure; all other dogs are alfve. Results describing the exposure aerosol characteristics and estimated achleved initial lung burden for the animals that inhaled one of the two yellowcake forms are shown in Tables 4.1 and 4.2. 
Table 4.1 .

Results of Beagle Dog Exposures to Aerosols of Yellowcake Powder Containing 100\% Ammonium Diuranate

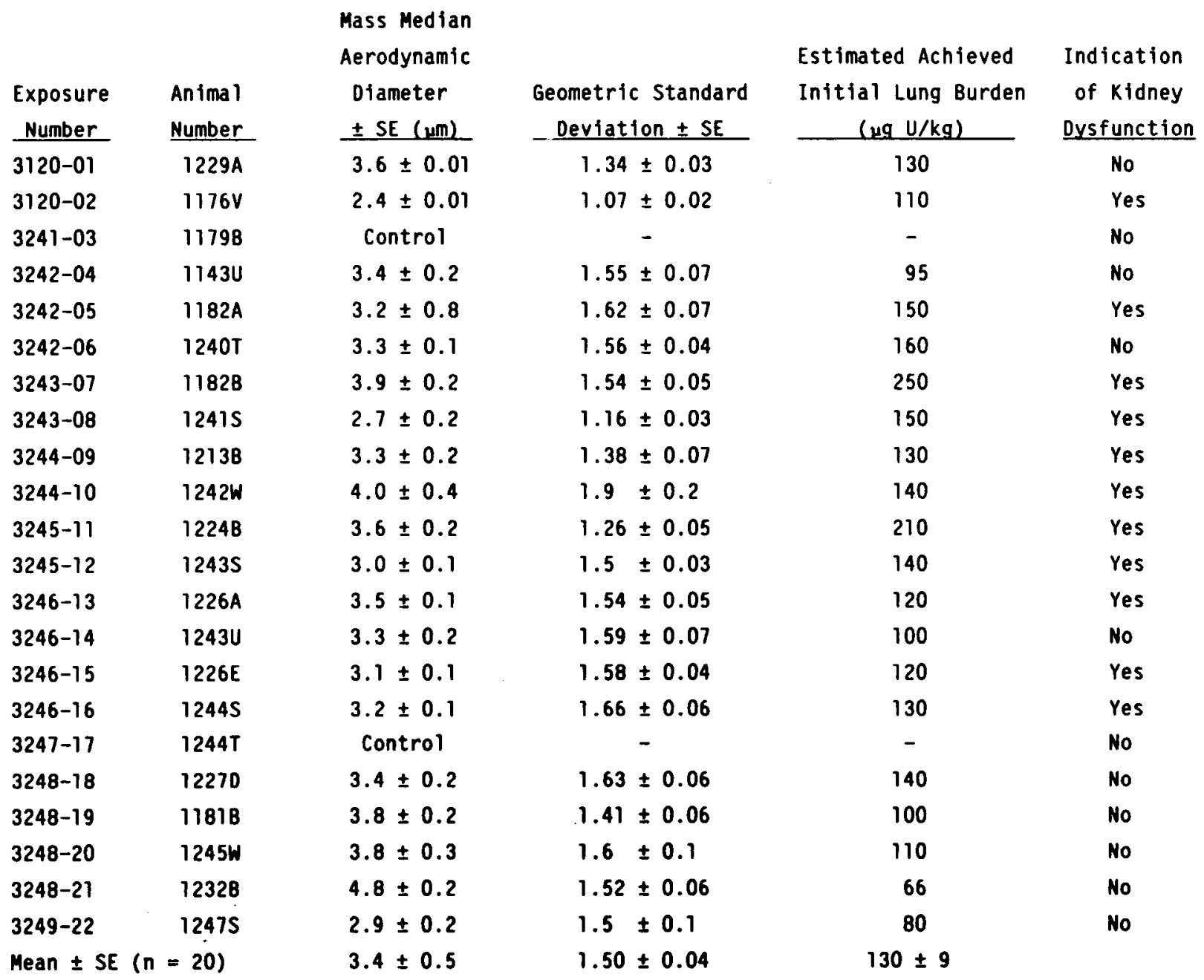


Table 4.2.

Results of Beagle Dog Exposures to Aerosols of Yellowcake Powder Containing $99 \% \mathrm{U}_{3} \mathrm{O}_{8}$

\begin{tabular}{|c|c|c|c|c|c|}
\hline $\begin{array}{l}\text { Exposure } \\
\text { Number } \\
\end{array}$ & $\begin{array}{l}\text { Animal } \\
\text { Number }\end{array}$ & $\begin{array}{l}\text { Mass Median } \\
\text { Aerodynamic } \\
\text { Diameter } \\
\pm S E(\mu \mathrm{m}) \\
\end{array}$ & $\begin{array}{c}\text { Geometric Standard } \\
\text { Deviation } \pm S E \\
\end{array}$ & $\begin{array}{l}\text { Estimated Achieved } \\
\text { Initial Lung Burden } \\
(\mathrm{gg} \mathrm{U} / \mathrm{kg}) \\
\end{array}$ & $\begin{array}{l}\text { Indication } \\
\text { of Kidney } \\
\text { Dysfunction }\end{array}$ \\
\hline $3121-23$ & $1145 S$ & $2.6 \pm 0.2$ & $1.7 \pm 0.1$ & 160 & No \\
\hline $3121-24$ & $1178 \mathrm{G}$ & $3.1 \pm 0.1$ & $1.5 \pm 0.1$ & 130 & No \\
\hline $3121-25$ & $1148 S$ & Control & - & - & No \\
\hline $3292-26$ & $1181 \mathrm{~A}$ & $1.9 \pm 0.1$ & $1.5 \pm 0.1$ & 130 & No \\
\hline $3292-27$ & $1220 \mathrm{C}$ & $1.5 \pm 0.1$ & $1.5 \pm 0.1$ & 190 & No \\
\hline $3292-28$ & $1174 T$ & $2.2 \pm 0.6$ & $1.9 \pm 0.3$ & 120 & No \\
\hline $3292-29$ & $1176 \mathrm{~T}$ & $2.7 \pm 0.1$ & $1.4 \pm 0.1$ & 110 & No \\
\hline $3293-30$ & $1221 \mathrm{~B}$ & $2.7 \pm 0.1$ & $1.7 \pm 0.1$ & 110 & No \\
\hline $3293-31$ & $1240 S$ & $3.0 \pm 0.1$ & $1.5 \pm 0.04$ & 160 & No \\
\hline $3294-32$ & $1242 T$ & $2.3 \pm 0.1$ & $1.6 \pm 0.1$ & 140 & No \\
\hline $3294-33$ & $1222 B$ & $3.3 \pm 0.2$ & $1.5 \pm 0.1$ & 130 & No \\
\hline $3294-34$ & 12220 & $2.9 \pm 0.2$ & $1.6 \pm 0.1$ & 120 & No \\
\hline $3294-35$ & $1245 \mathrm{~T}$ & $2.9 \pm 0.3$ & $1.7 \pm 0.1$ & 150 & No \\
\hline $3295-36$ & $1247 T$ & $2.4 \pm 0.1$ & $1.8 \pm 0.1$ & 190 & No \\
\hline $3295-37$ & $1235 A$ & $2.7 \pm 0.2$ & $1.8 \pm 0.1$ & 160 & No \\
\hline $3295-38$ & $1236 \mathrm{~A}$ & $2.6 \pm 0.2$ & $1.7 \pm 0.1$ & 200 & No \\
\hline $3295-39$ & 12368 & Control & - & - & No \\
\hline $3295-40$ & $1248 S$ & $7.7 \pm 2.3$ & $3.2 \pm 0.7$ & 100 & No \\
\hline $3296-41$ & $1248 T$ & $3.2 \pm 0.1$ & $1.6 \pm 0.04$ & 110 & No \\
\hline $3296-42$ & $1223 A$ & $3.6 \pm 0.2$ & $1.5 \pm 0.1$ & 110 & No \\
\hline $3297-43$ & $1237 A$ & $3.2 \pm 0.2$ & $1.6 \pm 0.1$ & 120 & No \\
\hline $3297-44$ & $1250 T$ & $3.0 \pm 0.3$ & $1.8 \pm 0.1$ & 180 & No \\
\hline \multicolumn{2}{|c|}{ Mean \pm SE $(n=20)$} & $3.0 \pm 0.3$ & $1.7 \pm 0.1$ & $140 \pm 7$ & \\
\hline
\end{tabular}


Use of filter sampling data to calibrate the nephelometer assumes that the particle size distribution of the aerosol remains constant during sampling. This assumption might not be warranted in some cases. However, the nephelometer was used to monitor the exposure aerosol concentration and overcome a major limitation of filter sampling, the time required to determine the amount of uranium on the filter by reflectance fluorometry (a minimum of $24 \mathrm{~h}$ ).

Initial lung burdens estimated using breathing parameters and aerosol concentrations measured during exposure were approximately $65 \%$ of the desired value and approximately $7 \%$ of the $L D_{50} / 30$ day dose for dogs given a single injection of $\mathrm{UO}_{2}\left(\mathrm{NO}_{3}\right)_{2}$ solution (Ref. 4.7). More refined estimates of the initial lung burden for each animal will also be made when the results of tissue and excreta analyses for uranium content become available for individual animals. The low intensity of gamma radiation from natural uranium precludes the use of external whole-body counting in this study.

Eleven dogs exposed to the more soluble yellowcake (containing $100 \%$ ammonium diuranate) have shown changes in biochemical indicators of renal dysfunction (Table 4.1). No such biochemical changes have been observed for dogs exposed to the less soluble form (containing > $99 \% U_{3} 0_{8}$, Table 4.2). Dog 1213B (Table 4.1), sacrificed on schedule at 4 days after exposure, had elevated glucose levels and albumin in urine above pre-exposure values. Dog 12415 had elevated glucose levels and albumin in urine at 8 days after exposure. Dogs identified as having possible kidney dysfunction had elevated glucose levels $(250-3000 \mathrm{mg} / \mathrm{d} 1)$ and protein $(100-1000 \mathrm{mg} / \mathrm{dl})$ in urine at 8 days after exposure. Control animals had normal levels of $0-0.25 \mathrm{mg} / \mathrm{d}$ for these indicators. In addition, elevated levels of $30-50 \mathrm{mg}$ (control value $=15 \mathrm{mg} \%$ ) blood urea nitrogen and $2.2-4.3$ $\mathrm{mg} \%$ creatinine (control value $=0.8-1.1 \mathrm{mg} \%$ ) were measured at 8 days after exposure. These elevated levels returned to normal at 16 days after exposure. Histopathological examination of kidney tissues from dogs that had biochemical evidence of kidney dysfunction is in progress; however, the dysfunction was possibly caused by acute tubular necrosis in the proximal tubules (Ref: 4.1 ) that was repaired by approximately 16 days after exposure.

These results show clearly that only the dogs exposed to the more soluble yellowcake form showed evidence of kidney toxicity, indicating that the content of ammonium diuranate in yellowcake aerosols is important for health protection purposes.

The occurrence of kidney dysfunction cannot be quantitatively related to the estimated initial lung burden now. The dogs that experienced kidney dysfunction (Table 4.1) had estimated initial lung burdens of $150 \pm 13 \mu \mathrm{g} \mathrm{U} / \mathrm{kg}$ body weight (mean $\pm S E$ ), and dogs with normal $\mathrm{kidney}$ function had estimated initial lung burdens of $106 \pm 11 \mu \mathrm{g} / \mathrm{kg}$. These values are not significantly different at the $95 \%$ confidence level. A more quantitative treatment of the doseresponse relationships between inhaled yellowcake and kidney toxicity will be possible when results of analyses for uranium content in tissues and excreta become available during the coming year.

\section{REFERENCES}

4.1 E. G. Damon, A. F. Eidson, F. F. Hahn, W. C. Griffith, Jr., and R. A. Guilmette, "Comparison of Early Lung Clearance of Yellowcake Aerosols in Rats with In Vitro Dissolution and Infrared Analysis," Health Physics (in press).

4.2 R. E. Alexander, "Applications of Bloassay for Uranium," Directorate of Regulatory Standards, U. S. Atomic Energy Comission, WASH-1251, Superintendent of Documents, U. S. Government Printing office, Washington, OC, 1974. 
4.3 Occupational Health Experience with Uranium, M. E. Wrenn, ed., ERDA-93*, 1975.

4.4 A. F. Eidson, "An Improved Technique for Aerosolization of Ory Powders of Industrial Uranium and Plutonium Mixed-oxide Nuclear Fuel Materials," Radiation Dose Estimate and Hazard Evaluations for Inhaled Airborne Radionuclides, Annual Progress Report, JuTy 1, 1978-June 30, 1979, J. A. Mewhinney, Project Coordinator, NUREG/CR-7458, LF-71, pp. 5-10, 1980*.

4.5 R. A. Guilmette, "Analytical Methods for the Quantitative Determination of Uranium in Biological and Nonbiological Materia1," Biological Characterization of Radiation Exposure and Dose Estimates for Inhaled Uranium Milling Effluents, Annual Progress Report, March 1979-March 1980, LMF-76, NUREG/CR-1669, pp. 23-26, 1980*.

4.6 B. B. Boecker, F. L. Aguilar, and T. T. Mercer, "A Canine Inhalation Exposure Apparatus Utilizing a Whole-Body Plethysmograph," Health Physics 10, 1077-1089 (1964).

4.7 P. W. Durbin and M. E. Wrenn, "Metabolism and Effects of Uranium in Animals," Occupational Health Experience with Urantum, Wrenn, M. E., ed., pp. 68-129, ERDA-93, VA, 1975*.

*Avallable from the National Technical Information Service, Springfield, VA 22161. 


\section{Publications}

1. A. F. Eidson and J. A. Mewhinney, "In vitro Solubility of Yellowcake Samples From Four Uranium Mills and the Implications for Bioassay Interpretations," Health Physics 39, 893-902 (1980).

2. A. F. Eidson and W. C. Griffith, Jr., "Techniques for Yellowcake Dissolution Studies In vitro and Their Use in Bioassay Interpretation." Health Physics (in press).

3. A. F. Eidson and E. G. Damon, "Characteristics of Yellowcake Aerosols Sampled in Operating Uranium Mills," Health Physics (in press).

4. E. G. Damon, A. F. Eldson, F. F. Hahn, W. C. Griffith Jr., and R. A. Guilmette, "Comparison of Early Lung Clearance of Yellowcake Aerosols in Rats with In Vitro Dissolution and Infrared Analysis." Health Physics (in press).

5. A. F. Eidson, "In vitro Dissolution of Commercial Yellowcake and Comparisons with Available Human Data," International Conference, Radlation Hazards in Mining: Control, Measurement, and Medical Aspects, M. Gomez, Ed., American Institute of Mining, Metallurgical, and Petroleum Engineers, Inc., pp. 1073-1078, 1981.

\section{Presentations}

1. A. F. Eidson and J. A. Mewhinney, "In Vitro Dissolution of Uranium Product Samples from Four Uranium Mills," 24th Annual Meeting of the Health Physics Society. Philadelphia, PA, July 8-13, 1979.

2. A. F. Eidson, "In Vitro Solubility of Yellowcake Samples From Four Uranium Mills and the Implications for Bioassay Interpretation," 25th Annual Conference on Bioassay, Environmental and Analytical Chemistry, Las Vegas, Mevada, October 31-November 1, 1979.

3. A. F. Eidson, "Comparison of Techniques for In vitro Yellowcake 0issolution Studies," 25th Annual Meeting of the Health Physics Society, Seattle, WA, July 20-25, 1980.

4. A. F. Eidson, "Characteristics of Uranium Milling Aerosols, "Meeting of Radiation Safety Officers and Members of the Wyoming Mining Association, Casper, WY, August 29, 1980.

5. A. F. Eidson, "Characteristics of Uranium Yellowcake Aerosols Sampled in Operating Uranium Mills," 26th Annual Meeting of the Health Physics Society, Louisville, KY, June 21-25, 1981.

6. A. F. Eidson, "In vitro Dissolution of Commercial Yellowcake and Comparison with Available Human Data," International Conference on Radiation Hazards in Mining: Control, Measurement, and Medical Aspects, Golden, Co, October 4-9, 1981.

7. E. G. Damon and A. F. Eidson. "Six-Month Studies of the Translocation and Retention of Uranium in Rats Exposed by Inhalation of Aerosols of Yellowcake Samples From Two Uranfum Mills," Rio Grande Chapter, American Industrial Hygiene Association and the Health Physics Society Joint Meeting, Albuquerque, NM, October 5-6, 1981.

8. E. G. Damon and A. F. Eidson, "Translocation and Retention of Urantum in Rats Exposed by Inbalation of Aerosols of Yellowcake Samples from Two Uranium Mills." 27th Annual Meeting of the Health Physics Socfety, Las Vegas, NV, June 26-July 1, 1982. 


\section{Abstracts}

1. A. F. Eidson and J. A. Mewhinney, "In vitro Dissolution of Uranium Product Samples from Four Uranium Mills," Health Physics 37, 821 (1979).

2. A. F. Eidson, "Comparisons of Techniques for In Vitro Yellowcake Dissolution Studies," Health Physics 39, 1050 (1980).

3. A. F. Eidson and E. G. Damon. "Characteristics of Uranium Yellowcake Aerosols Sampled in Operating Uranium Mills," Health Physics 41, 847 (1981).

4. E. G. Damon and A. F. Eidson, "Translocation and Retention of Uranium in Rats Exposed by Inhalation of Aerosols of Yellowcake Samples from Two Uranium Mills, " Health Physics 43, 143 (1982). 
NRC FORM 335

(111.81)

U.S. NUCLEAR REGULATORY COMMISSION

BIBLIOGRAPHIC DATA SHEET

1. REPPRT NUMEER (Assigned by DOCI

NUREG/CR -3745

LMF - 108

4. TITLE AND SUBTITLE (Ada Volume No., if eporopriare) Biological Characteri-

2. (Leave bienk)

zation of Radiation Exposure and Dose Estimates for Inhaled

Uranium MIlling Effluents (Annual Progress Report: Apri1 1, 3. ReCIPIENT'S ACCESSIONNo.

1982 - March 31, 1983)

7. AUTHOR(S)

A.F. Eidson, Project Coordinator

9. PERFORMING ORGANIZATION NAME AND MAILING ADDRESS (Include Zip Code)

Inhalation Toxicology Research Institute

Lovelace Biomedical and Environmental Research Institute

P.0. Box 5890

Albuquerque, NM 87185

12. SPONSORING ORGANIZATION NAME AND MAILING ADORESS (Include Zip Code)

Division of Health, Siting and Waste Management

Office of Nuclear Regulatory Research

U.S. Nuclear Regulatory Commission

Washington, D.C. 20555

5. DATE REPORT COMPLETED

\begin{tabular}{l|l}
\hline MONTH & YEAA \\
April & 1984
\end{tabular}

DATE REPORT ISSUEO

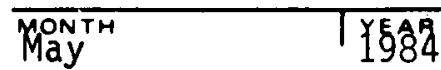

6. (Leave bionk)

B. (Leave bronk)

10. PROJECT/TASK/WORK UNIT NO

11. FIN NO.

A 1222

13. TYPE OF REPORT

Technical

15. SUPPLEMENTARY NOTES

PERIOO COVEREO (Inclusive dates/

April 1, 1982 - March 3], 1983

16. ABSTRACT 200 words or less A quantitative infrared absorption method for yellowcake allowed the fraction of ammonium diuranate in a mixture to be determined accurately within $7 \%$ and the $\mathrm{U}_{3} \mathrm{O}_{8}$ fraction within $13 \%$. The composition of yellowcake from six operating mills ranged from nearly pure ammonium diuranate to nearly pure $U_{3} 0_{8}$ : A study of retention and translocation of uranium after subcutaneous implantation in rats was done. The results showed that $49 \%$ of the implanted yellowcake cleared from the body with a half-time in the body of 0.3 days, and the remainder was cleared with a half-time of 11 to 30 days. Twenty dogs exposed to a more soluble yellowcake form inhaled aerosols producing an estimated initial lung burden of 130 micrograms of $U$ per kilogram of body weight. Aerosols inhaled by dogs exposed to a less soluble yellowcake form averaged an estimated initial lung burden of 140 micrograms of $U$ per kilogram of body weight. Biochemical indicators of kidney dysfunction that appeared in blood and urine 4 to 8 days after exposure to the more soluble yellowcake showed significant changes in dogs, but levels returned to normal by 16 days after exposure. No biochemical evidence of kidney dysfunction was observed in dogs exposed to the less soluble yellowcake form.

uranium, aerosol, yel lowcake deposition, inhalation, exposure dose, solubility, mill, health bioassay, rats, dogs, wounds, infrared analysis, fuel cycle

170. IDENTIFIERS'OPEN-ENDED TERMS

18. AVAILABILITY STATEMENT

Unl imited rats, dogs, uranium

fuel cycle, yellowcake 